Article

\title{
Restrictions of Historical Tissues on Urban Growth, Self-Sustaining Agglomeration in Walled Cities of Chinese Origin
}

\author{
Haosu Zhao ${ }^{1, *}$, Bart Julien Dewancker ${ }^{1, *}$, , Feng Hua ${ }^{2}$, Junping $\mathrm{He}^{2}$ and Weijun Gao ${ }^{1}$ (D) \\ 1 Department of Architecture, Faculty of Environmental Engineering, The University of Kitakyushu, \\ Wakamatsu-ku Hibikino 1-1, Kitakyushu 808-0135, Japan; weijun@kitakyu-u.ac.jp \\ 2 Faculty of Architecture and City Planning, Kunming University of Science and Technology, \\ No.727 South Jingming Rd, Chenggong District, Kunming 650500, China; 13312160@kust.edu.cn (F.H.); \\ 13312155@kust.edu.cn (J.H.) \\ * Correspondence: y7dbb407@eng.kitakyu-u.ac.jp (H.Z.); bart@kitakyu-u.ac.jp (B.J.D.); \\ Tel.: +81-93-695-3245 (B.J.D.)
}

Received: 9 June 2020; Accepted: 15 July 2020; Published: 21 July 2020

check for updates

\begin{abstract}
This article uses a fractal observation to help delineate the constraints placed by multiple city walls on the growth of historical East Asian cities. By applying advanced technologies from economic geography and fractal indices, a staged scaling process within urban dimension coherence can be applied to both indices. In this study, a discovery is proposed based on the urban organism concept that is capable of indicating a proportional intra-urban structure from a fundamental wall-bounded urban element (local specificity) to other greater walled spatial properties (global variables). This local specificity potentially performs approximate scaling regularities, and spatially denotes an average historical threshold of urban growth for its overall size, with similar scaling law constraints. This finding involves territorial, urban planning, and ancient architectural perspectives, providing a historical and local response to the expansion of contemporary cities. By employing growing fractal estimation, data processing enables the logarithmic city size to be obtained by measuring each wall's specific features using the Ordinary Least Squares (OLS) method. On the basis of two-dimensional allometric scaling patches, a spatial unfolding mechanism is utilized to reproduce these dynamic changes with city walls as a result of the human trajectories in time geography.
\end{abstract}

Keywords: historical agglomeration; urban equilibrium; allometric scaling; walled city; organizational hierarchy

\section{Introduction}

As a morphological phenomenon, cities have maintained relatively stable structural dynamics and texture complexity in a long historical period to maintain an urban equilibrium, which has recently transitioned towards a fast expansion due to urban sprawling, thus placing an increasing anthropogenic effect on the natural environment. More importantly, the uncontrolled population growth and the increased burden on environmental resources will eventually lead to a major dependence on the intensive use of pesticides and fertilizers [1], ultimately pushing the integrity of many biomes' biodiversity to beyond the limits of safety [2]. Therefore, research on the upper limit of the urban growth scale in a historical period will provide a comparison for the current excessive population growth and, at the same time, will remind us to describe spatiotemporal changes in urban growth boundaries from the perspective of historical growth by using some simple and clear growth mechanisms.

The current trend is to use a clustering algorithm to sample cities as environmental and socioeconomic scenarios, which represent urban expansion through statistical cluster aggregation and 
a discrete agglomeration boundary definition. In line with the history of urbanization, truly evolved urban areas also invoke a spontaneous result from their embryonic state, given that it shows a connection to the "traditional individual's development trajectory of the overall organization" when attracting and disseminating capital and information flows [3,4]. Those features that are considered to be localized in global chain command controls are generalized as institutional settings for correlated urban patterns in reasonable endogenous processes and represent the structural inhomogeneity of the material (urban) fabrics being created. According to the long line of literature on urban geography and economics, the simulated agglomeration model for urban growth, however, still focuses on quantifying the environmental and socioeconomic outcomes of cities with respect to their sizes (i.e., the city size for population outcomes), mainly confronting a polarized city size, defined as the whole city (system) size with urban scaling law domains [5-8]; internal city structures have networks and form pattern controls [9-13], yet they comparatively contribute to a universal definition by which cluster integration can be used to help classify site ontologies from urban areas across various macro variables of different cities with differing sizes. This approach, in line with the concept of underlying self-organization [14], uses a biological analog to express the way in which urbanized land use varies and correlates with the city size distribution, laying emphasis on the scaling laws and organizational tensions across the organism's metabolism and location of the relative temporal and spatial dynamics. The related literature has been principally empirical and focused on the following: the urban size distribution of a city's population, particularly its power-law distribution [15]; the city's relational driving force to aggregate $[16,17]$; and the structural endogeneity of the growth framework in various domains [13,18-20].

However, despite the fact that all the aforementioned delineations agree that urban agglomeration is not only a geographically continuous entity but also a closely integrated spatial existence of networks (people, cargo, capital and information) and nodes (central and peripheral cities) [21], the fuzzy physical boundary and multiple perspectives from multiple ideologies still make quantitative criteria a huge and complex responsive system, remaining in universal or fluid dimensions and having no consensus on unfolding such dimensional sedimentations through any relational trajectories of locational potentials for growth. In other words, research in this field still lacks the concept of a 'material substratum' that affords the physical and socioeconomic benefits of cities' allometry from their initial emergence to each appearing growth radius of single or multiple production center aggregates. Nordbeck [22], Martin [23], and Batty and Longley [24] have characterized such observational sprawling within the allometric equation. We herein continue using this biological scaling law to delve into fundamental elements of the city organism.

On the other hand, alongside the rapid changes and activities from non-fixed growth driving forces, developed cities' pattern formation endures increasingly complex dynamics from the original structural interactions to the subsequent urban renewal and population growth. This occurs in contrast to the cities' historical textures (fabric), such as street networks, old quarters, ramparts, and heritage building arrangements, as well as the rises and falls of various sequences of technology cycles. Thus, when looking at the evolution process of a city's geometric pattern and material fabric from the perspective of non-linear development, the city in its embryonic developmental stage has provided a relatively stable state that involves the overall organizational structure in consistent development from a self-sustainable urban equilibrium (order) to a dynamic non-equilibrium (chaos) [14,25], evolutionarily anchoring the agglomeration object into each random land consumption starting point. Regardless of the spatiotemporal unfolding practice, little attention has been paid to this urban agglomeration delineation with territory-associated features [26-29]. In other words, these studies are believed to provide insights that illuminate the unpacking of agglomeration bodies, aiming to link the cities' activities resulting from an endogenous intra-urban process with the fundamental land-use properties as locales.

For this case study, 21 multiple-wall-enclosed historical cities in East Asia are utilized to establish a database to assess the universal macroscopic pattern of the pre-industrial city model. Hence, 
the well-kept wall records allow for a population investigation by using the physical size proxy of unavailable historical population data [30]. Depending on the pre-industrial wall-enclosed feature, the material built-up environment of these cities, including buildings, wards, city blocks, and communities with walled boundary classifications, have also been considered to preserve an introverted spatial living mode for different land-use properties, where most of these amenities have demonstrated their territory isolation in accordance with the compound construction for respective environmental and socioeconomic outcomes.

Under the organismic concept, the physical form of these cities has maintained their overall embryonic state through continuous wall mosaics, granting a leap-frog proportion to sample coherence land consumption laws. In the context of the endogeneity of cities' systems, multiple walls have physically limited the expansion of city sizes and created an organic force from the center to the periphery [31,32]. These walls also demonstrate a spontaneous motivation for capital allocation and coalescence of material tissues [12,33], which can assist in implementing urban clustering supported by different systems of behavior, along with the correspondence of its physical environment and socioeconomic outcome as appropriate urban scaling scales. Hence, in the case of urban embryos surrounded by these walls, their historical development status can be summarized as a kind of organizational elasticity in which the tissues are all glued together by a common growth process.

On the basis of these grounds, the purpose of this article is to find the scaling regulation principle formed by the historical growth state of Sino-influenced wall formation. The variable of their envelope tissue is hopefully expressed through a simple set of scaling mechanisms. At the same time, the two polarized aspects of urban modeling discussed in the aforementioned literature (globally integrated cities' systems and locally heterogeneous internal structures) are herein represented by the aim of empirical analysis for the organic force fueling urban growth in historical walled boundary constraints, namely, reflected by the urban profile contingent (the homothetic scaling level from the same location) and locational growth radius (an endogenous force from allometric consistency). The contingent of urban profiles is capable of being analyzed through diffusion and aggregation thinking, for which the area-perimeter method is used to pursue their hypothesized scaling center from the Ordinary Least Squares (OLS) estimate, whereas the locational growth radius is restored by allometric scaling that uses the estimated city's logarithmic size to trace the hierarchical endogeneity of the entire urban dimension within different environmental and socioeconomic benefits. As a successive boundary of urban growth restrictions, we assume that all studied cities in wall enclosures are completed artifacts as organisms. Consequently, we expect that the urban individual element will be locally proportional to the whole city's growth, including both allometric and homothetic growth. This involves examining a political or social network in this research that forms both the urban systems and internal structures located in the same actual places and that embodies the emerging urban agglomeration.

This article is organized as follows: the associated literature and theoretical background, as well as data interpretations of Sino-influenced wall-enclosed city models, are introduced in Section 2. Section 3 introduces the database that is accessed with a methodological innovation and generation of the dynamic model, involving the spatial organization evaluation for the endogenous growth level and structural stability of each walled city. In Section 4, we summarize and discuss the estimated results of our findings. Finally, the complementary theory and possible contributions are discussed in Section 5.

\section{Sino-Influenced Walled City Formation}

\subsection{Social and Historical Context in Chinese Walled Cities}

Wall-enclosed cities formed in ancient East Asia were probably most highly influenced by 'Sinocentric' cultural traditions for their similar special planning morphology and socio-spatial delimiting [34], which artificially categorizes their socioeconomic and geographic evolution patterns as an organization delineation of urban cluster integration. Herein, the wall enclosure, as the fundamental urban built-up indicator, materially emphasizes the localized spatial living patterns emanating with 
respect to their land-use property of relational organization hierarchy. Its globally attributed walled compound structures of clustering significance are attributed to all introverted urban profiles within the same generic metric of locational potential quantification. Each individual living mode that constitutes a localized building environment (urban fabric) is demarcated by the multiple-wall enclosure complex that separates private and quiet residential spaces from the public and chaotic urban environment [32]. This special urban classification is generally supported by the 'centralized planning economy' for each social community and political network in a highly concentric manner. Moreover, the hierarchical wall clustering process has facilitated a proportional land consumption rate that makes the whole city structure a self-organized system for its increase in total size and unchanging population densities, especially for some historical capital cities in their embryonic periods. (The ancient Chinese developed a unified urban theory involving spatial form, artistic planning and aesthetics values, all of which are now the unique wealth inherited and developed by East Asian countries whose societies were once a part of Chinese civilization and whose scripts are still widely acknowledged as derivatives of Classical Chinese script, which is broadly alive in today's Japan, Korea, Mongolia and Vietnam [35]). Under the mutual influence from cultural dissemination, the doctrine for such urban form development is commonly inherited by the historic states in the mainland and peripheral regions of East Asia.

Upon locating the historical agglomeration state within significant wall enclosures, each wall forming an urban profile with its environmental and socioeconomic development has received the most consideration possible in associated literature [36], since the wall and the tower should be the most distinguishable symbols marking a distinct urban space from the surrounding countryside [37]. The walled discrimination (a combined road network with the street plan from a walled-ward) [38] is commonly accepted as the spatial significance factor that indicates the consumption of land size properties and is employed as the manual proxy to clarify the population distribution [39]. In other words, the urban structure of Sino-influence walled cities is more inclined to "use the enclosure of the wall to replace the changes in a large number of land-use areas on the edge of the city, thereby describing the expansion of the city" [40], and the origin of the city, starting from proportional planning right from the very beginning [41], can prevent the tendency of the large discontinuity of closely settled areas haphazardly intermingled [42].

In view of endogenized urban land consumption, one of the ubiquitous locational factors used to link the agglomeration subject to a localized wall enclosure feature is the feudal monarchy domain land-use framework, which is a politically dependent territorial emphasis from which introverted spatial living patterns emanate. This essentially positions the origin of the entire urban system to be a certain local physical size, which can be specific to the wall-enclosing form of a certain public building scale. In this situation, the global socioeconomic outcomes that imprint urban agglomeration within the corresponded activities hierarchically invoke urban internal structures into the same allometric progress. These structures include the city edge, building envelope, planning layout, social aspects, and political administration. The global socioeconomic outcomes also adapt to the historical urban fabric, such as single buildings, patios, communities, districts, small towns, and other compound structures, in a homothetic scaling relationship according to their political representative generic allometry (Figure 1). Formally, the inner wall area encompasses a higher range of wall enclosures (up to the city boundary), and this higher-level area has a more complex socioeconomic activity environment. Such a strict division makes each wall enclosure adhere to respective social rank hierarchies and quantified in pieces of laps with at least four or five levels, while the dividing characteristics can commonly start from the wall-enclosed range from the hall, palace, imperial city, administrative city, town city, and outer city (Table 1). Each profile with respective urban dimensions has contributed differently to yield the environmental and socioeconomic benefits as homothetic scaling proportions. 


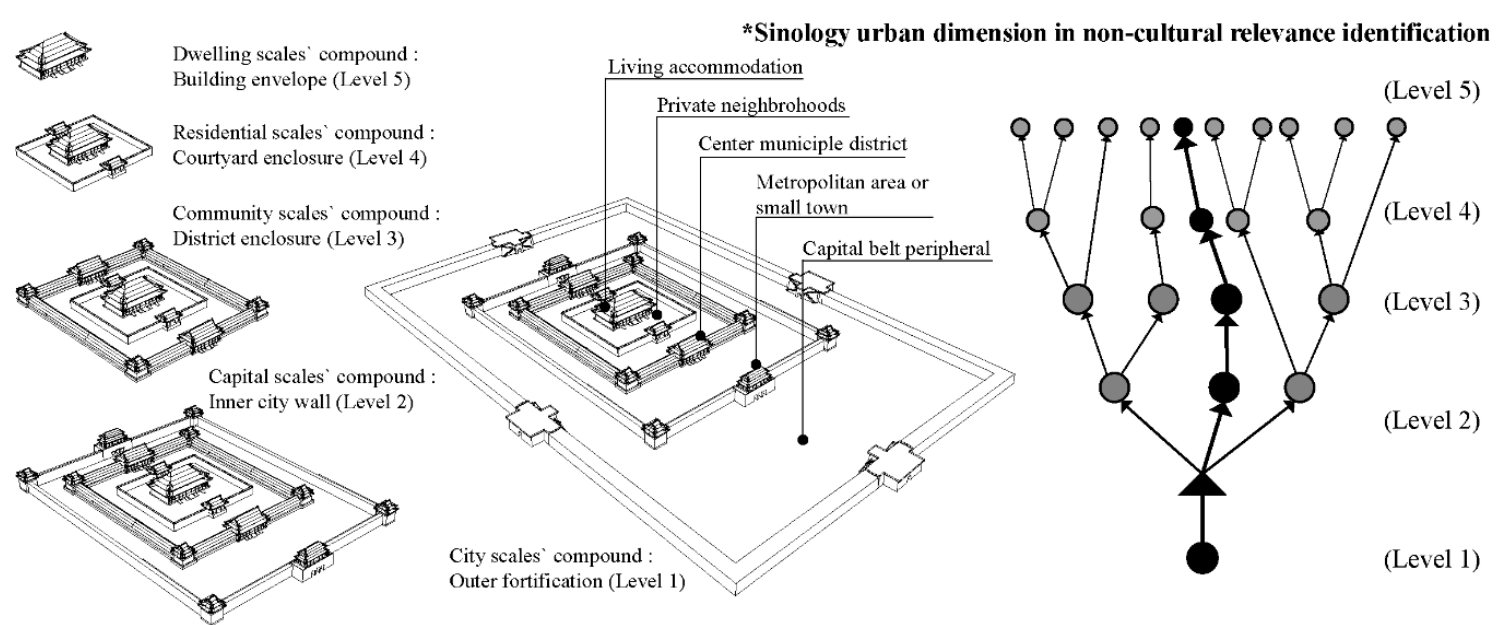

Figure 1. Walled spaces that are significant for urban cities with homothetic territorial features demarcated from their relational global force imprints in macro-levels.

Table 1. Dimension and organization hierarchy of wall enclosure urban profiles in a macrostructural to a microstructural process of Sinocentric land development using a scaling framework.

\begin{tabular}{llllll}
\hline \multirow{2}{*}{$\begin{array}{c}\text { Urban Spatial } \\
\text { Ranks }\end{array}$} & \multicolumn{2}{c}{ Space Centralized Dissemination } & \multicolumn{2}{c}{ Social Organization Hierarchy } \\
\cline { 2 - 6 } & Urban Enclosures & \multicolumn{1}{c}{$\begin{array}{c}\text { Living Pattern } \\
\text { Emanation }\end{array}$} & $\begin{array}{c}\text { Compound } \\
\text { Typology }\end{array}$ & $\begin{array}{c}\text { Social Class } \\
\text { (Political Case) }\end{array}$ & $\begin{array}{c}\text { Interacting } \\
\text { Type }\end{array}$ \\
\hline Rank 1 & City area & Socioeconomic activity & Agglomeration & Citizen & Society \\
Rank 2 & District area & Municipal & Capital area & Seignior & Bloc \\
Rank 3 & Residential quarters & Residential environment & Community & Cabal & Clan \\
Rank 4 & Courtyard & Neighborhood & Courtyard & Royalties & Family \\
Rank 5 & Interior space & Individual space & Housing & Emperor & Individual \\
\hline
\end{tabular}

\subsection{Data Acquisition and Processing}

The empirical analysis of this study was based on the notion that all Sino-influenced cities impart morphological statistics on the surrounding walls with respect to their geographic spatial characteristics, and all these cities have existed as capitals of the country at certain historical times. A large amount of historical investigation work collected all earlier experience and theoretical literature to help reconstruct the characteristics of these cities (for details, see Table A1 in Appendix A). At the same time, by using the data gathered manually as a reference, the existing preserved wall sites were corrected using remote sensing images. The materials adopted the principle notion of "China's core and peripheral regions" from Shuji Funo [43] and experience wide distribution, currently including mainland China, Mongolia, Korea, Japan, Vietnam, and some peripheral regions of East Asia. Most of the data came from the long-term research project of historical literature, which is mainly led by the Chinese Academy of Social Sciences (CASS) [44], Nara National Research Institution for Culture Properties (Japan) [45], and Culture Heritage Administration of Korea (CHA) [46], which are known for their historical approach to urban recovery, heritage conservation, and urban planning study. A large group of public databases on urban form, walled city size, stratified walled areas, and walled city envelopes from exhaustive surveying was recorded, enabling us to access the original allometry status of those walls surrounding cities from various geometric measures. All the data, including of 21 historic walled cities, could support the empirical analysis. Most of the databases have well-maintained detailed information on each wall's structure and can help us restore its pre-modern city type. Their distribution locations are marked in Figure 2.

Combining the remote sensing images from Google Maps with the complementary data from correlated historical literature and drawings, the major source of the formed area and perimeter of each wall-enclosed urban dimension can verify their data accuracy through manual error correction. 
All related remote sensing images were downloaded from the LocaSpace Viewer center [47] of the commercial software. We first converted the images of these cities into the GCS_WGS_1984 geographic coordinate system and used Asia_Lambert_Conformal_Conic as the project coordinate system. Subsequently, we used CAD software to refer to historical documents and drawings in creating vector graphics for cities in the form of city walls. By applying the spatial calibration tool in Esri ArcGIS, and by setting the geometric feature points to the appropriate spectral features and key landmarks, the shape and perimeter recorded by the vectored wall surrounding the city and the historical wall relics actually saved or excavated the performed alignment transformation. The hierarchical wall-embedded city forms and boundaries could then train their cross-sectional levels within the geometrical feature clipping and extraction, in which their spatial extrusion showed an exponential relationship from the center to frontiers. This geographic information with spatial hierarchy classification and manual corrections are illustrated in the array in Table 2 to reflect the actual city size.

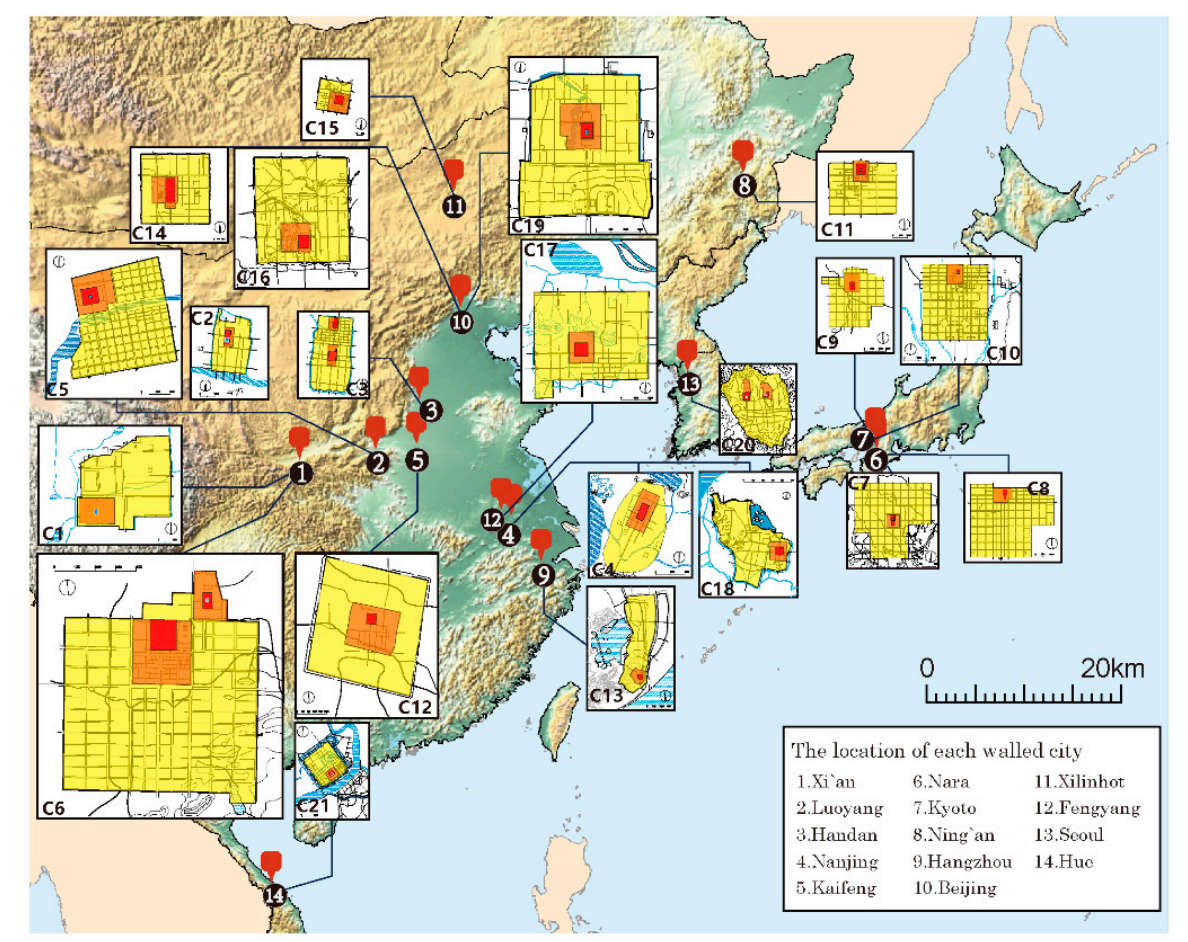

Figure 2. Wall concentric distribution pattern in different historical places with the current location or city names, East Asia.

The scaling laws of the Sino-influence city in wall enclosures can be obtained by modeling and depicting the two-dimensional geometric patterns of its introverted living space and increased land occupation. Then, each individual mode of private landscape extension can characterize its potential (scaling) trajectory contingent on relational global and local activities [48] with formed diffusion or aggregation. It resembles the intrinsic urban tissue variables within single command controls. Meanwhile, as central dissemination proceeds with wall enclosure constraints, structural tension can be found from the walled spatial property extensions and can be relatively scaled in accordance with the core place size for its encapsulated spatial unit [49].

Generally, when applying wall enclosures as a ubiquitous feature of urban cluster statistics, the extensive part of the city in subsequent fractions is assumed to be able to proportionally regress to its embryonic form and function as a structurally self-sustaining or sometimes self-regulating organization. Thus, if the current city size greater or smaller than the former $(S)$ is $S+a$ or $S-$ a, respectively, then the city in an organism can vary under a power-law relationship. As the most common symbol of a walled city's clustering, the introverted spatial enclosure feature allowed us to 
correlate the size of the fundamental element in urban growth with the overall structure scale through the control of chain instructions while, at the same time, linking the existing enclosure. The evolution law between forms serves as a prediction of the space-enclosing pattern in a larger area [50]. In order to describe this process, the impact of all urban growth models, including the observed evolution of urban geographic space, as well as various artificial infrastructures and political and cultural activities, were conceptualized as a simple rule-controlled operating mechanism [9] that made a meaningful attempt to simulate walled cities.

Table 2. Wall-enclosed city areas and perimeters with respect to different clustering representatives of a specific growth trajectory (political domains) in 21 Sino-influenced historical cities, East Asia.

\begin{tabular}{|c|c|c|c|c|c|c|c|c|c|c|c|}
\hline \multirow[b]{2}{*}{ Abbr. } & \multirow{2}{*}{ Capital Name } & \multicolumn{2}{|c|}{ Outer Wall } & \multicolumn{2}{|c|}{ Inner Wall } & \multicolumn{2}{|c|}{ Palace Wall } & \multicolumn{2}{|c|}{ Courtyard Wall } & \multicolumn{2}{|c|}{ Hall Building } \\
\hline & & $\begin{array}{l}\text { Perimeter } \\
\text { P (Km) }\end{array}$ & $\begin{array}{c}\text { Area } \\
\mathrm{A}\left(\mathrm{Km}^{2}\right)\end{array}$ & $\begin{array}{l}\text { Perimeter } \\
\text { P (Km) }\end{array}$ & $\begin{array}{c}\text { Area } \\
\mathrm{A}\left(\mathrm{Km}^{2}\right)\end{array}$ & $\begin{array}{c}\text { Perimeter } \\
\mathbf{P}(\mathrm{Km})\end{array}$ & $\begin{array}{c}\text { Area } \\
\mathrm{A}\left(\mathrm{Km}^{2}\right)\end{array}$ & $\begin{array}{c}\text { Perimeter } \\
\mathbf{P}(\mathrm{m})\end{array}$ & $\begin{array}{c}\text { Area } \\
A\left(m^{2}\right)\end{array}$ & $\begin{array}{c}\text { Perimeter } \\
\mathbf{P}(\mathrm{m})\end{array}$ & $\begin{array}{c}\text { Area } \\
\text { A }\left(\mathrm{m}^{2}\right)\end{array}$ \\
\hline $\mathrm{C} 1$ & Chang'an (Han) & 25.700 & 35.749 & 8.800 & 4.767 & N/A & N/A & 1221 & 80,534 & N/A & N/A \\
\hline C2 & Luo yang (Han) & 14.184 & 9.156 & 4.010 & 0.838 & 2.815 & 0.396 & 1360 & 103,891 & 338 & 6779 \\
\hline $\mathrm{C} 3$ & Ye & 15.800 & 14.467 & 4.410 & 1.008 & 3.508 & 0.606 & N/A & N/A & N/A & N/A \\
\hline $\mathrm{C} 4$ & Jian kang & 18.054 & 21.743 & 8.647 & 4.095 & 3.464 & 0.638 & N/A & N/A & N/A & N/A \\
\hline C5 & Luo yang (Tang) & 27.900 & 45.389 & 9.444 & 5.502 & 4.174 & 1.088 & 985 & 60,057 & 306 & 5248 \\
\hline C6 & Chang'an (Tang) & 42.511 & 86.755 & 7.647 & 3.256 & 3.277 & 0.465 & N/A & $\mathrm{N} / \mathrm{A}$ & N/A & N/A \\
\hline C7 & Fujiwara Kyo & 20.250 & 18.873 & 3.694 & 0.853 & 2.003 & 0.191 & 577 & 20,379 & N/A & N/A \\
\hline $\mathrm{C} 8$ & Heijo Kyo & 22.263 & 25.715 & 4.588 & 1.228 & 1.857 & 0.151 & 420 & 10,643 & 137 & 1049 \\
\hline C9 & Nagaoka Kyo & 16.819 & 13.090 & N/A & N/A & N/A & N/A & 468 & 13,564 & 125 & 903 \\
\hline C10 & Heian Kyo & 19.455 & 23.530 & 4.878 & 1.474 & 1.368 & 0.087 & 676 & 20,103 & 149 & 1132 \\
\hline C11 & Balhae & 16.400 & 16.086 & 4.827 & 1.437 & 2.708 & 0.455 & 767 & 36,708 & 163 & 1447 \\
\hline $\mathrm{C} 12$ & Bianjing & 28.518 & 52.942 & 11.550 & 8.480 & 2.521 & 0.394 & N/A & N/A & N/A & N/A \\
\hline $\mathrm{C} 13$ & Lin'an & 17.994 & 11.381 & 2.725 & 0.495 & 1.096 & 0.061 & N/A & N/A & N/A & N/A \\
\hline C14 & Jin Zhongdu & 18.690 & 22.055 & 9.797 & 5.338 & 5.05 & 1.451 & N/A & N/A & N/A & N/A \\
\hline C15 & Yuan Xanadu & 8.805 & 4.852 & 5.620 & 1.972 & 1.755 & 0.328 & N/A & N/A & N/A & N/A \\
\hline C16 & Dadu & 28.600 & 50.896 & 9.289 & 5.103 & 3.45 & 0.732 & 1281 & 96,406 & 230 & 3156 \\
\hline C17 & Ming Zhongdu & 30.365 & 48.904 & 7.670 & 3.617 & 3.702 & 0.855 & N/A & N/A & N/A & N/A \\
\hline $\mathrm{C} 18$ & Nanjing & 35.267 & 43.240 & 9.950 & 4.643 & 3.572 & 0.803 & N/A & N/A & N/A & N/A \\
\hline $\mathrm{C} 19$ & Beijing & 34.368 & 65.055 & 11.104 & 6.773 & 3.44 & 0.736 & 1353 & 96,253 & 205 & 2428 \\
\hline $\mathrm{C} 20$ & Seoul & 21.443 & 23.088 & 3.900 & 0.692 & 2.404 & 0.329 & 507 & 15,852 & 121 & 896 \\
\hline $\mathrm{C} 21$ & Hué & 10.746 & 5.016 & 2.646 & 0.387 & 1.269 & 0.1 & 387 & 8627 & 159 & 1551 \\
\hline
\end{tabular}

\section{The Mathematics of Walled Cities: Allometric Growth}

Despite non-cultural relevant conditions, the gear shifts between each walled urban enclosure are still considered to have the traits of a city system's relational dynamics of the tissue variable, where the walled-bounded agglomeration body and the localized urban enclosure feature are both relationally responsive to the individual spatial living modes. This locally situated process uses an initial emergence to constraints on cities from their priority growth force to impose a localized urban unit size for mass quantities. Thus, in this study, the wall-delimited land occupation of the Royal Assembly Hall, a building type, could be used as a representative of the basic unit of the city. While the range of wall enclosure spatial characteristics encompasses the scaling relationship of the spatial life model, it represents and provides a self-similarity based on actual location factors for the entire multi-layered wall enclosure system. For such geospatial observation of spatial organization diffusion and boundary evolution (in multiple overlapping cities' perimeters), a fractal scaling behavior can be appropriately adaptive to these locational emanated growth boundaries and describe their structural intensity within different wide ranges and diffusion scales.

Prevalent methods of fractal estimation are mainly implemented by the area-radius scaling method [51-54], the area-perimeter scaling method [55-57], and the box-counting method [58-60]. The area-perimeter scaling method that we used in this paper aims to reveal the evolution mode of city morphology by switching between different homogeneous growth boundaries. This method has been recently employed to characterize the urban size evolution in a fractal description [61]. In practice, the walled area-perimeter features on a geometrical basis are equivalent in construction by the system of scaling equations to the numerical illustration of the dimension relation [62] and to equipotential evolution of scaling hierarchies [18,63-65]. This approach applies the scaling relationship to reveal the urban system's spatiotemporal evolution dynamics. 


\subsection{Fractal Measurement of Urban Dimensions Evolution}

Under the description of the fractal dimension, the change in the geometric measure between the non-Euclidean dimension indices ensures the consistency of the evolution of the spatial form during the extrusion change and can be established in the traditional shape lineage from linear space to the correspondence of the columnar space. The concept here is that such a clarified dimension relationship can only be found in situations where the dimension value of geometric measure $X$ is equal to another measure $\mathrm{Y}$ with geometrical proportionality; hence, we can say that they have a dimensional consistency $[66,67]$. The dimension consistency has a proportional relationship, such as $Y \propto X$ or $Y=k X$, where $\mathrm{k}$ is a proportionality constant for the coefficient. Between different measures, the consistency of the dimension means that, genealogically, any spatial quantity $\mathrm{M}$ (their volume amount 'Mass'), such as length $\mathrm{L}$, area $\mathrm{A}$, and volume $\mathrm{V}$, can have their relationship expressed as follows:

$$
L^{1 / 1} \propto A^{1 / 2} \propto V^{1 / 3} \propto M^{1 / d},
$$

where the index $d f$ refers to a general dimension [60]. If the value emerges as an integer, it denotes the traditional Euclidean object. For instance, $d f=0$ defines a point, $d f=1$ defines a line, $d f=2$ defines a plane with its surface, and $d f=3$ defines a cube.

In the case of wall enclosures of a city in practice, the wall-surrounded city form's territorial features can be regarded as having general 2D dimensions $d f=2$ for the Euclidean plane and boundary perimeters as $d f=1$ for a line. In the fractal theory of dimension consistency, the geometric pattern that varies from area to boundary involves more than a Euclidian dimensional process in which their relational spatial measurements of the accordant shape index are all attributed to a quantitative spatial mass, and the dimension evolution is estimated through the regression analysis of the Ordinary Least Squares (OLS) method $[60,68]$. Their dimensional relationship in a fractal follows the power-law expression:

$$
\left(\frac{P}{k}\right)^{1 / D_{l}}=A^{1 / 2}
$$

where $P$ refers to the urban boundary perimeter, which demarcates the irregular form shape with a successive enclosed walled curve, while $A$ refers to the bounded distribution area. For the boundary dimension in the fractal relationship, $D_{l}$ indicates a cascade proportion that derives the urban size (geographical) from the conventional dimension to a fractal abundance, and $k$ is the proportional constant reflecting the complexity of boundary allometry.

As a geometric measure, $D_{l}$ is used to express the exponential relationship in the spatial dimensional relationship, and it is expressed by the concept of "initial size" because it reveals the ratio required to distinguish between different conventional dimensional indexes. By using the data from the real-world system with geometric measures, it is easy to evaluate the value of $k$ and $P / k$ through a regression analysis, where $P / k$ can be regarded as the instant quantity of spatiotemporal growth that is available in both geometric and mathematical descriptions. The data measured from the perimeter (line) and area (plane) are used to describe the spatial allometry of urban agglomerations, and their dimensional consistency can satisfy the following relationship:

$$
D_{l}=\frac{2 \ln (P / k)}{\ln (A)}
$$

In order to avoid the overestimation of insignificant sizes of values in the OLS method, the morphological measurement related to the two-dimensional area has been improved for identifying the quasi-dimension $D_{l}$ estimate $[51,62,69]$ as follows:

$$
D_{b}=\frac{\left(1+D_{l}\right)}{2}
$$


where $D_{b}$ denotes the revised boundary dimension and is designed to establish compatibility in the dimension consistency of fractal abundance. By using the regression analysis with $b=D_{l} / d=D_{l} / 2$, the value of $D_{b}$ can be derived from $D_{l}$, as their linear correlations are characterized by the log-linear regression and reflect an initially fixed entire dimension quantity.

\subsection{Spontaneous Growth and Spatial Allometric Scales}

In the general fractal growth model, the underlying mechanism of self-similarity [70] is often considered to be able to respond appropriately to the growth trajectory of correlations that exist in natural and social systems. If a city can use the spatial expansion resulting from its endogenous growth as a physical diffusion to its neighbors and can subdivide the possibility of such scaling due to diffusion in a cascading land distribution method, then the continuous emergence of this growth phenomenon, that is, its evolution law, can be summarized as a structural elasticity controlled by the central government (Figure 3). Their spatial scaling has been thus generalized as allometric growth $[24,67]$. Moreover, in many cases, the scale index of allometric growth plays a more important role than the fractal dimension in the spatial analysis of urban systems [71]. This relationship actually illustrates a hyperbolic relationship during urban form aggregation, and the correlated forms emerge as territory features and adapt through the fractal dimension description.

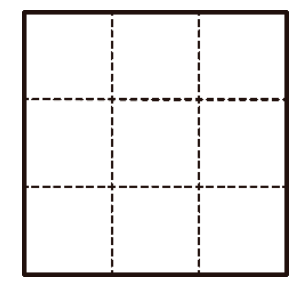

Level 0

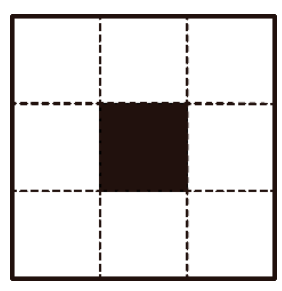

Level 1

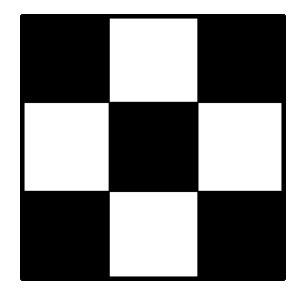

Level 2

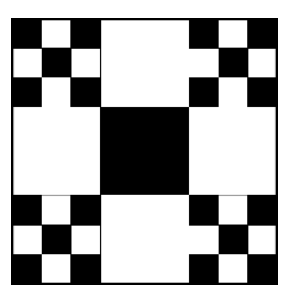

Level 3

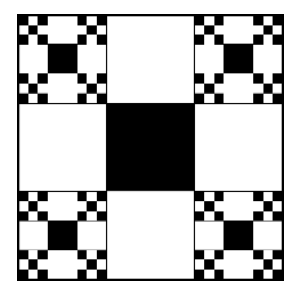

Level 4

Figure 3. Regular spatial emergence steps in growth property subdivisions with its spontaneous driving force diffusion.

Given that the scale of the city enclosed by the wall is based on the evolution of the environment and the social economy, the amount of space enclosed by the wall of the city can be regarded as the volume of the entire space aggregate, which is in (2), and the area-perimeter model for allometric growth listed within can be written as:

$$
(k P)^{1 / D_{b}}=A^{1 / D_{f}} .
$$

On the basis of the proportion regulation from the structure constant of coefficient $k$, the scaling relationship on both the linear and square dimensions of fractal parameters in (5) provides a quasi-allometric scale as the initial fractal dimension, which we suggest in terms of non-dimensional features to estimate the urban form instantaneously [72]. For the urban area of growth elasticity, we have:

$$
A_{f 1}=(k P)^{1 / D_{f}} .
$$

For $D_{f}$ and $D_{b}$ in the initial dimension value $D_{l}$ correlation, we have a hyperbolic relationship, as:

$$
\frac{1}{D_{f}}=1-\frac{1}{2 D_{b}}
$$

where the form enclosure $1 / D_{b}$ of more boundary complexity adaptivity is used to derive the more fractal dimension $1 / D_{f} . D_{f}$ here represents the form emerging dimension, which departs from the initial place as the formula $D_{f}=1+1 / D_{l}$. Depending on the corresponding non-dimension, we can derive 
the value from $k P$ as the entire quantity of the fractal property that enables access to any dimension segment with fixed geometry.

Through regression analysis of (2), (5), and (7), the scaling relationship in an index can be found in the allometry of spatial organization, and the dimensional relationship corresponding to their scaling scale can be defined as:

$$
\sigma=\frac{D_{f}}{D_{b}}=\frac{A(\varepsilon)}{A_{f 1}}
$$

where $\sigma$ refers to the scaling exponent variation for the revised area-perimeter allometry, and 'proportionally' implies a ratio between two cross-sectional measurements of self-similarities, while $\varepsilon$ means the changing of areas and length or other geometric measures, $D_{f}$ stands for the fractal entity, and $D_{b}$ is the spatial boundary variable. By applying this scaling exponent relationship with Equation (6), we can generalize the structural self-sustaining model of urban form evolution into power-law degenerate growth as:

$$
A(\varepsilon)=A_{f 1}{ }^{\sigma}=(k P)^{-\sigma}
$$

where $A(\varepsilon)$ represents the entire quantity from 2D planar allometry, and $A_{f 1}$ denotes the OLS estimate of the initial emerging size (mean logarithm size). This method enables the approximation of the core place of an organization in proportional growth. Conversely, by applying such a hypothesized organization kernel, material dependence form features can be utilized as a hub for the localized growth potential from relational trajectories of global responsiveness, approaching the entire organization quality by tracing the initial scales of allometry.

\subsection{Allometric Regularity of Spatial Extension}

Under the structure interaction condition, the growth potential of any locale (such as the building-occupied site in this study) is assumed to be responsive to the universal range of its private land use probability with allometric scaling. In this process, it is important to confirm the regularity and stability of this locational scaling during the valid city form evolution, that is, how these special locations gradually allocate their growth potential to different evolutionary subdivisions in a cascade formation. Herein, the entire emergence of perimeter length (edges) and allometric scales (mass) are coupled with double logarithmic relations $\left(D_{b}\right.$ and $\left.D_{f}\right)$, using fractal abundance to describe the boundary complexity $\left(D_{l}\right)$ within continuous scaling. In other words, the consistency of the urban outcome in locational potentials yields an inversed power-law relationship that reflects outside force perturbances on urban size distributions (total mass in 1) with its flattening pattern evolutions.

For any portion of the global force domain organization, a suitable structure strength has always existed for its cross-sectional tissues (even single-mode) with a respective aggregate state to adapt, while in a fractal, the non-dimension quantity $M$ is preferred to depict those aggregation entities as $(k P)=M$, where $\hat{M}$ denotes the estimated value and $\underline{M}$ is the potentiality locale. By applying the basic fractal algorithm, we attempt to depict such a spatial evolution by yielding the allometric scaling, which is given as:

$$
A(\varepsilon)=\hat{M}^{\left(1 / D_{f 1}\right)^{\sigma}} .
$$

If $S$ is taken as the actual urban size (in physical space) related to location potential in walled cities, then the change in its overall organizational size can be characterized by the proportional function $\mathrm{f}(\mathrm{s})$, which is written as:

$$
f(S)=1-\frac{A_{1}}{A(\varepsilon)}=1-\frac{M^{1 / D_{f 1}}}{M^{\left(1 / D_{f 1}\right)^{\Delta \lambda}}} \quad \forall M \geq \underline{M} .
$$

If $f(s)$ in (11) is assumed to be the proportion of the socioeconomic level $\mathrm{R}$ related to the location growth radius when the non-dimensional quantity is quantified, then $\mathcal{R}=[1-f(s)]$. In order to 
observe the interference caused by the consistency of the structure or other external factors on the existing scaling law, we take the natural logarithmic rate as:

$$
\ln \mathcal{R}=-\left(1 / D_{f 1}\right)^{\Delta \lambda} .
$$

Thus, on the basis of the scaling regularity from the allometric relationship, the locational scaling trajectory at different endogenous states can cross-sectionally obtain their structural tension variation $\Delta \lambda$ from the corresponding proportion regulation. In this research, the consistent radius from cities of their homothetic wall enclosures provides such regularity for describing their organic force and socioeconomic activities.

\section{Empirical Analysis and Results}

According to the processed data and the previous formula, in a historic walled city, the sequence of urban contour scaling (as a hierarchy of homothetic scaling) and the locational growth radius (tissue tightness due to allometric laws) can be divided into two steps for analysis. The analytic framework used to process the historical agglomeration state, illustrated in Figure 4, was as follows.

For walled urban profiles with the whole city area scales (trajectory), we first used the regression method to evaluate the proportionality coefficient $k$ of the form fractality from each walled urban profile (Equations (1) and (2)). Then, we assessed the mean logarithmic size's dimension $D_{l}$ and its boundary dimension $D_{b}$ from each local estimated wall enclosure for preparing the subsequent calculations (Equations (3) and (4)). Furthermore, each of these staged allometric profiles with respect to the cross-sectional scaling $\sigma$ could be calculated from the quasi-least-squares $A_{f}$ for its represented core place size of different growth states to regress (Equations (5)-(8)). Additionally, by observing the trend line fit of the area-perimeter regression from each local estimated urban profile, we could then globally build an experimental model to check if this contingent urban scaling from an individual walled locale to the whole city's boundary was divided into appropriate cross-sections or not, that is, the comparatively homothetic scaling (unfolding) process for the walled urban clusters in general algorithm controls. The multiple-wall enclosure patterns from 21 Sino-influence cities could provide this part's estimation as an acquired database.

When the radius from one potential location was taken as the internal structure of the whole city, the interval regularity between the local-global radius could then be considered to be the organic force of the organizational structure performance. This radius attributed an overall urban system's linkage that is proportionally associated with the exponent of some locational growth possibilities, and therefore, a local response between each initial increase in land area and the whole aggregate mass $\mathrm{M}$ could be obtained by estimating the minimum logarithm size Af1 from the walled urban elements' locations (Equations (8)-(10)). Afterwards, the environmental and socioeconomic outcomes differentiated from this initial growth site, even to the divergent edge of each layer with the wall as the boundary, could be developed by the accumulation of the allometric scaling index $\sigma$. This process was described dynamically. The fractal spectrum $\Delta \lambda$ and correlated parameters herein can help characterize the consistent allometry of 'scaling regularities' that 'measure' the structure endogeneity with organic force fluctuations (Equations (10)-(12)). In this part, nine cities had successfully preserved their political domain urban profiles (including their imperial audience hall for a socially organized center to represent it) that are available for the act of locational growth potential and that materially characterize both the physical and socioeconomic evolutions within the same particular locales. 


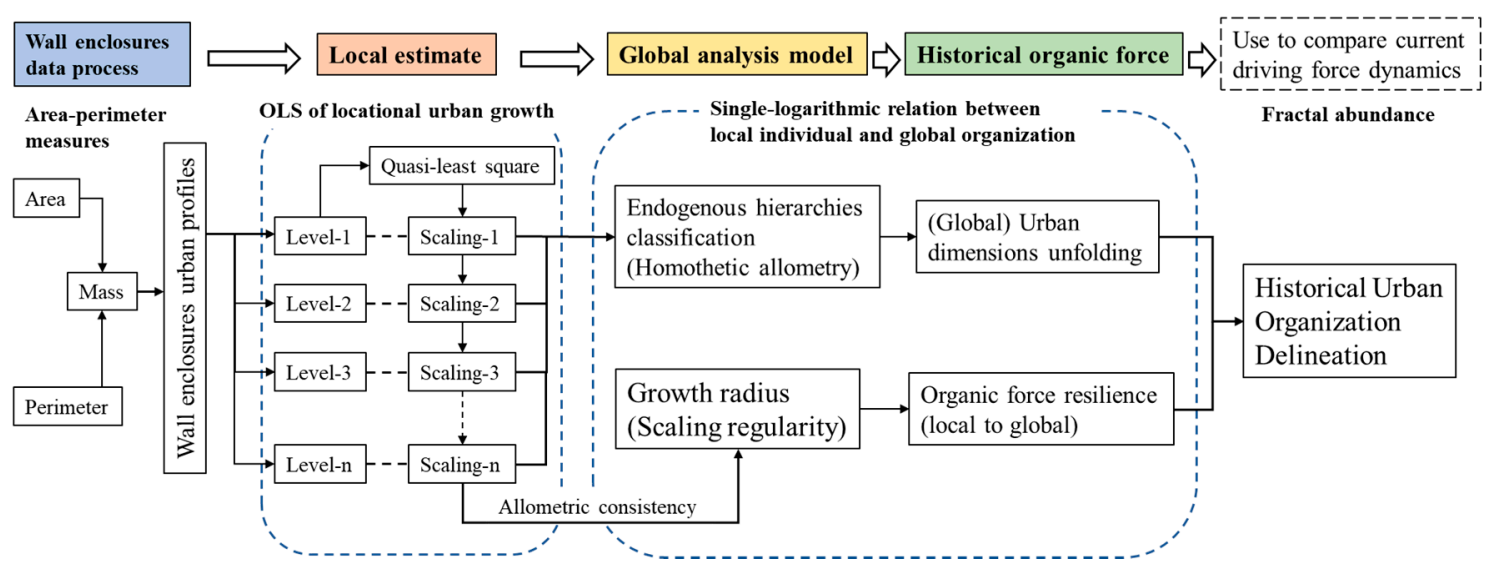

Figure 4. The workflow of historical urban organization delineation.

\subsection{Growth Stage of Wall Enclosure Urban Profiles}

On the basis of the Ordinary Least Square (OLS) estimate, each wall-bounded urban profile could be evaluated from the highly integrated agglomeration boundary (urban form boundary) to the individual evolution potential (local territory features) for responsive relational trajectories. By implementing the area-perimeter regression, the curve of the trend line in each local growth estimation (Figure 5) was employed to demonstrate the fitting of how much the wall enclosure feature deviated from the same scaling sequence or same cross-sectional hierarchy that can represent their allometric stages as the generic proportion of an urban empirical model, where the goodness-of-fit $R^{2}$ indicates the local estimation deviation, and $k$ implies a boundary fractality for the contents of relational growth potentialities. Depending on the successive boundary of each wall-enclosed urban profile, the area-perimeter scaling exponent $b$ can be directly associated with allometry consistency. By taking natural logarithms of both sides of Equation (2), the area-perimeter scaling approach to analyzing enclosed city forms could yield a linear relation as depicted below:

$$
\ln \left(\frac{P}{k}\right)=\ln k+\frac{D_{l}}{2} \cdot \ln A=\ln k+b \cdot \ln A,
$$

where $\ln (P / k)$ estimates the logarithmic size of growth emergence, and $b$ is the scaling exponent for the form dimension $D_{l} / 2$. The database from Table 2 allowed us to calculate the least squares of each wall-enclosed area hierarchically. By applying Equations (4)-(7), we could calculate $D_{l}, D_{b}$ for the fractal parameter and $D_{f}$ for further estimation, where $D_{l}$ stands for the initial boundary dimension of the wall-enclosed area, $D_{b}$ is revised from $D_{l}$ as a quasi-dimension value and $D_{f}$, is the fractal form dimension.

For the global fractal basis analyzed with regression results from different urban profiles of the same cross-section level, series values were given and tabulated in Table 3, including the general scaling exponent of wall-enclosed area $b$, the goodness-of-fit $\mathrm{R}^{2}$, and the boundary complexities $k$ (or the coefficient of evolution consistency). The $k$ value here also represents the proportional coefficient for the least square of some cross-sectional urban profile's emergence, which in this research was the minimum proportion of locational growth to the urban endogeneity, attributed to local fractal parameters. The correlated value involves the non-dimensional value $D_{l}$ from Equation (3), the boundary dimension $D_{b}$, and the form dimension $D_{f}$ from (4) and (5) accordingly, which are all tabulated in Table 4 after the empirical calculation. 


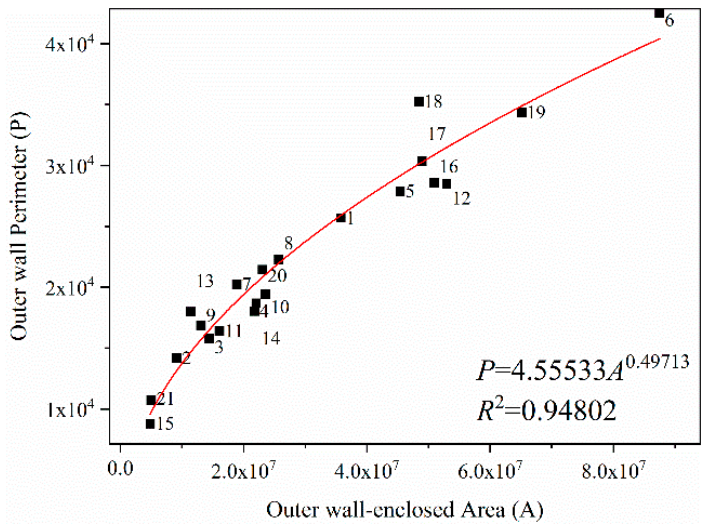

(a) Outer fortification for urban dimension feature

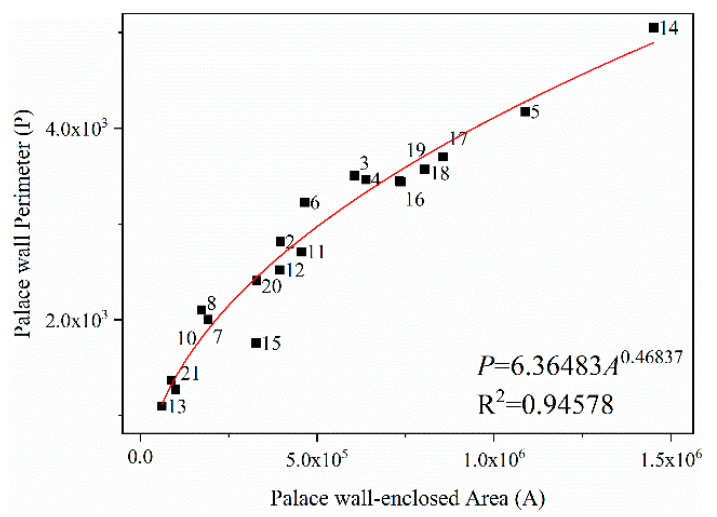

(c) Palace enclosure for urban dimension feature

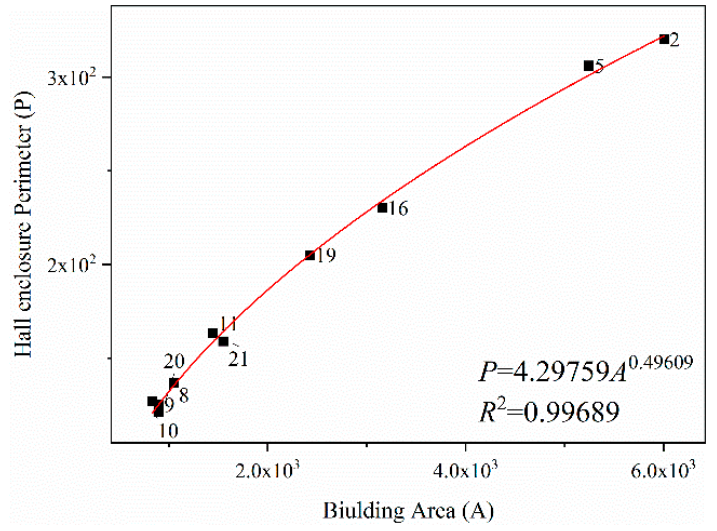

(e) Building envelope for urban dimension feature

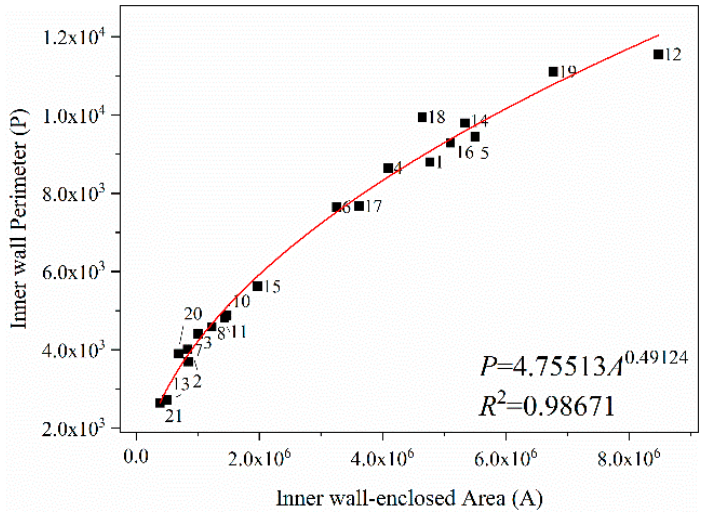

(b) Inner city wall for urban dimension feature

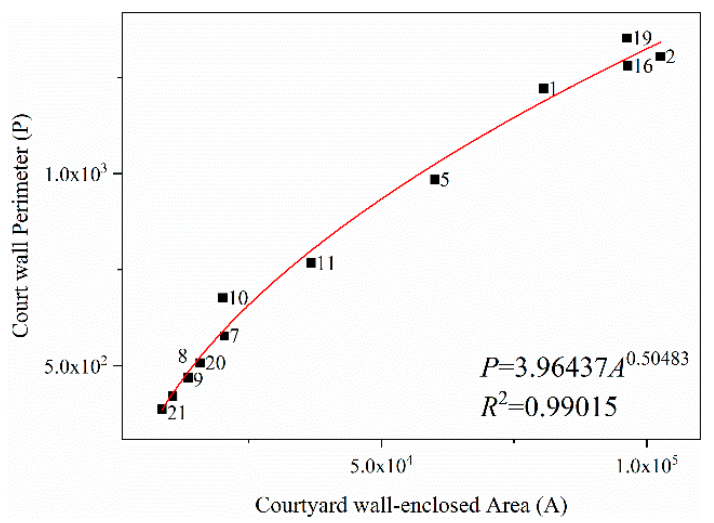

(d) Courtyard enclosure for urban dimension feature

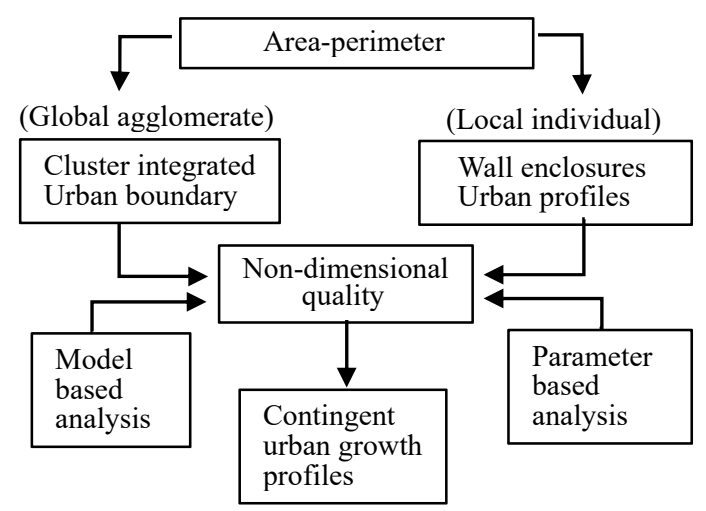

(f) Analysis process separated in global and local estimate

Figure 5. The area-perimeter scaling relationships between wall-enclosed areas and boundary perimeters of each wall enclosure features with different compound clusters. (a) fit result of mass and shapes of outer fortification bounded cities' enclosure; (b) fit result of mass and shapes of inner-city wall bounded cities' enclosure; (c) fit result of mass and shapes of palace wall bounded cities' enclosure; (d) fit result of mass and shapes of courtyard wall bounded cities' enclosure; (e) fit result of mass and shapes of building envelope bounded cities' enclosure; (f) schematic diagram for both the local cities and their universal and empirical model based on the area-perimeter scaling. 
Table 3. The global fractal parameters of the walled city unfolding model in different scaling levels of potential trajectories with homothetic cross-sections.

\begin{tabular}{|c|c|c|c|c|c|c|}
\hline \multirow{2}{*}{ Wall-Enclosed Urban Stratify } & \multicolumn{3}{|c|}{ Original Result (Model Basis) } & \multicolumn{3}{|c|}{ Revised Result } \\
\hline & $\mathbf{k}$ & $\mathbf{b}$ & $\mathbf{R}^{2}$ & $D_{1}(2 b)$ & $D_{b}=\left(1+D_{1}\right) / 2$ & $D_{f}=1+1 / D_{1}$ \\
\hline Outer wall & 4.5553 & 0.49713 & 0.94802 & 0.99426 & 0.99713 & 2.00577 \\
\hline Inner wall & 4.75513 & 0.49124 & 0.98671 & 0.98248 & 0.99124 & 2.01783 \\
\hline Palace wall & 6.36483 & 0.46837 & 0.94578 & 0.93674 & 0.96837 & 2.06753 \\
\hline Courtyard & 3.96437 & 0.50483 & 0.99015 & 1.00966 & 1.00483 & 1.99043 \\
\hline Hall envelope & 4.29759 & 0.49609 & 0.99689 & 0.99218 & 0.99609 & 2.00788 \\
\hline Average & 4.7874 & 0.49153 & 0.97351 & 0.983064 & 0.991532 & 2.017888 \\
\hline
\end{tabular}

The notion here is that when allometric growth transitions from a linear dimension or a shape dimension to another non-Euclidean measurement, the structural evolution process with cross-sectional growth layers emerges and follows the self-affine fractal for its growth radius variation. Combining (Table 3) the universal fractal model obtained by the area-perimeter calculation and (Table 4) the estimation of the local fractal parameters of every single instance, we could determine whether it is the boundary dimension $D_{l}$ or the revised boundary dimension $D_{b}$ and the form dimension $D_{f}$, and they both showed a similar fractal property in their respective dimensions' measures. This indicates applicability for the global model's patch in which all estimated urban dimensions can follow a universal (political domains) growth framework to unfold. This suggests homothetic cross-sections that characterize all Sino-influence walled cities into the same hierarchy classification of endogeneity. As a result of the historical agglomeration state situation, each cross-sectional walled urban profile harboring different socioeconomic activities can express their locational growth state, contingently associated with the hyperbolic relationship between $D_{b}$ and $D_{f}$ for their scaling exponent $-\sigma$ from Equations (7) and (8). While their least-squares value $A_{f}$ in the non-dimensional fractal calculated from (6) and (9) can be categorized as the hypothesized aggregation center for the growth potential locales (Table 5), the correlated local average values of the global analysis model to be adopted are tabulated in Table 6.

After calculating nine well-preserved city walls (Table 5), the least-squares area $A_{f 1}-A_{f 5}$ in each of their cross-sectional growth stage and their central-peripheral-associated scaling exponent $-\sigma$ associated with them were calculated locally and subsequently averaged. The values are displayed separately and show a relatively fixed scaling relationship between each walled territory boundary and its assumed core place. In addition, for the quasi-least-squares area Af of the urban aggregates in each homothetic cross-section, their scaling ability shows an empirical constant from the macro-global to the micro-individuals in Table 1, which is the general scaling capacity of each endogenic hierarchy. Accordingly, the enclosure area of the city's outer fortification was $\sigma_{f 1}=2.01289$, which is the upper scale of the city size, and the inner city wall was $\sigma_{\mathrm{f} 2}=2.03461$ as the capital scale; the palace wall range was $\sigma_{\mathrm{f} 3}=2.13545$ as the scale of the community; the scale of the courtyard fence, $\sigma_{\mathrm{f} 4}=1.98044$, is the scale of the living environment; the hall building enclosure range, $\sigma_{\mathrm{f} 5}=2.01493$, is the scale of the dwelling. As the global average, the mean scaling capacity of the cities' wall enclosing was close to 2.035 , suggesting a relatively constant proportionality for any locational potential to reach its maximum scaling range of urban boundaries' allometry. 
Table 4. Empirical and theoretical results of fractal parameters in different walled allometric stages.

\begin{tabular}{|c|c|c|c|c|c|c|c|c|c|c|c|c|c|c|}
\hline \multirow{2}{*}{ Abbr. } & \multicolumn{3}{|c|}{ Outer Wall } & \multicolumn{2}{|c|}{ Inner Wall } & \multicolumn{3}{|c|}{ Palace Wall } & \multicolumn{3}{|c|}{ Yard Wall } & \multicolumn{3}{|c|}{ Hall Wall } \\
\hline & $\mathrm{D}_{1}$ & $\mathrm{D}_{\mathrm{b}}$ & $\mathbf{D}_{\mathrm{f}}$ & $\mathrm{D}_{1}$ & $\mathrm{D}_{\mathrm{b}}$ & $\mathrm{D}_{\mathrm{f}}$ & $\mathrm{D}_{1}$ & $\mathrm{D}_{\mathrm{b}}$ & $D_{f}$ & $D_{1}$ & $\mathbf{D}_{\mathrm{b}}$ & $\mathrm{D}_{1}$ & $D_{b}$ & $\mathbf{D}_{\mathrm{f}}$ \\
\hline $\mathrm{C} 1$ & 0.9933 & 0.9967 & 2.0067 & 0.9785 & 0.9892 & 2.0219 & N/A & N/A & N/A & 1.0145 & 1.0073 & N/A & N/A & N/A \\
\hline $\mathrm{C} 2$ * & 1.0036 & 1.0018 & 1.9964 & 0.9879 & 0.9939 & 2.0123 & 0.9452 & 0.9726 & 2.0579 & 1.0047 & 1.0024 & 0.9908 & 0.9954 & 2.0093 \\
\hline $\mathrm{C} 3$ & 0.9888 & 0.9944 & 2.0113 & 0.9885 & 0.9942 & 2.0117 & 0.9481 & 0.9741 & 2.0547 & N/A & N/A & N/A & N/A & N/A \\
\hline $\mathrm{C} 4$ & 0.9808 & 0.9904 & 2.0196 & 0.9859 & 0.9929 & 2.0143 & 0.9426 & 0.9713 & 2.0609 & N/A & N/A & N/A & N/A & N/A \\
\hline $\mathrm{C} 5$ * & 0.9892 & 0.9946 & 2.0109 & 0.9786 & 0.9893 & 2.0219 & 0.9332 & 0.9666 & 2.0716 & 1.0025 & 1.0013 & 0.9959 & 0.9979 & 2.0041 \\
\hline $\mathrm{C} 6$ & 0.9998 & 0.9999 & 2.0002 & 0.9846 & 0.9923 & 2.0156 & 0.9545 & 0.9772 & 2.0477 & N/A & N/A & N/A & N/A & N/A \\
\hline $\mathrm{C} 7$ & 1.0027 & 1.0014 & 1.9973 & 0.9747 & 0.9873 & 2.026 & 0.9457 & 0.9729 & 2.0574 & 1.0039 & 1.0019 & N/A & N/A & N/A \\
\hline $\mathrm{C} 8 *$ & 0.9957 & 0.9978 & 2.0044 & 0.9802 & 0.9901 & 2.0202 & 0.9616 & 0.9808 & 2.0399 & 1.0057 & 1.0029 & 0.9954 & 0.9977 & 2.0046 \\
\hline C9 & 1.0025 & 1.0012 & 1.9975 & N/A & N/A & N/A & N/A & N/A & N/A & 1.0028 & 1.0014 & 0.9904 & 0.9952 & 2.0097 \\
\hline $\mathrm{C} 10^{*}$ & 0.9849 & 0.9925 & 2.0152 & 0.9763 & 0.9881 & 2.0243 & 0.9434 & 0.9717 & 2.0599 & 1.0373 & 1.0186 & 1.0070 & 1.0035 & 1.9930 \\
\hline $\mathrm{C} 11^{*}$ & 0.9869 & 0.9935 & 2.0132 & 0.9765 & 0.9883 & 2.0240 & 0.9292 & 0.9646 & 2.0762 & 1.0019 & 1.0009 & 1.0000 & 1.0000 & 1.9999 \\
\hline C12 & 0.983 & 0.9916 & 2.0172 & 0.9773 & 0.9886 & 2.0233 & 0.9285 & 0.9642 & 2.0771 & N/A & N/A & N/A & N/A & N/A \\
\hline C13 & 1.0194 & 1.0097 & 1.9809 & 0.9686 & 0.9843 & 2.0324 & 0.9338 & 0.9668 & 2.0709 & N/A & N/A & N/A & N/A & N/A \\
\hline C14 & 0.9841 & 0.9921 & 2.0162 & 0.9852 & 0.9926 & 2.0150 & 0.9411 & 0.9706 & 2.0626 & N/A & N/A & N/A & N/A & N/A \\
\hline C15 & 0.9830 & 0.9915 & 2.0173 & 0.9762 & 0.9881 & 2.0244 & 0.8849 & 0.9424 & 2.1301 & N/A & N/A & N/A & N/A & N/A \\
\hline $\mathrm{C} 16^{*}$ & 0.9856 & 0.9928 & 2.0146 & 0.9812 & 0.9906 & 2.0192 & 0.9323 & 0.9662 & 2.0726 & 1.0069 & 1.0035 & 0.9879 & 0.9939 & 2.0122 \\
\hline C17 & 0.9946 & 0.9973 & 2.0055 & 0.9782 & 0.9891 & 2.0223 & 0.9321 & 0.9660 & 2.0729 & N/A & N/A & N/A & N/A & N/A \\
\hline C18 & 1.0121 & 1.0060 & 1.9881 & 0.9962 & 0.9981 & 2.0039 & 0.9311 & 0.9655 & 2.0740 & $\mathrm{~N} / \mathrm{A}$ & N/A & N/A & N/A & N/A \\
\hline $\mathrm{C} 19^{*}$ & 0.9926 & 0.9963 & 2.0075 & 0.9862 & 0.9931 & 2.0139 & 0.9316 & 0.9658 & 2.0735 & 1.0166 & 1.0083 & 0.9917 & 0.9958 & 2.0084 \\
\hline $\mathrm{C} 20^{*}$ & 0.9976 & 0.9988 & 2.0024 & 0.9978 & 0.9989 & 2.0022 & 0.9344 & 0.9672 & 2.0703 & 1.0033 & 1.0016 & 0.9819 & 0.9909 & 2.0184 \\
\hline $\mathrm{C} 21^{*}$ & 1.0067 & 1.0034 & 1.9933 & 0.9826 & 0.9913 & 2.0177 & 0.9196 & 0.9598 & 2.0875 & 1.0109 & 1.0055 & 0.9829 & 0.9915 & 2.0173 \\
\hline AVG & 0.9946 & 0.9973 & 2.0055 & 0.9821 & 0.9910 & 2.0183 & 0.9354 & 0.9677 & 2.0694 & 1.0092 & 1.0046 & 0.9924 & 0.9962 & 2.0076 \\
\hline
\end{tabular}

Note: * Denotes the full data acquirable in the wall surrounding the city of a social ordered hierarchy. 
Table 5. Scaling capacity (potentiality) from the core to the edge with respect to each wall-embedded urban enclosure for structure diffusion cross-sections.

\begin{tabular}{|c|c|c|c|c|c|c|c|c|c|c|c|c|}
\hline \multirow{2}{*}{ Abbr. } & \multirow{2}{*}{$\begin{array}{l}\text { Capital } \\
\text { Name }\end{array}$} & \multicolumn{2}{|c|}{ Outer Wall } & \multicolumn{2}{|c|}{ Inner Wall } & \multicolumn{2}{|c|}{ Palace Wall } & \multicolumn{2}{|c|}{ Yard Wall } & \multicolumn{2}{|c|}{ Hall Wall } & \multirow{2}{*}{$\begin{array}{c}\text { Realistic Built Scale } \\
\mathrm{A}_{5}\left(\mathrm{~m}^{2}\right)\end{array}$} \\
\hline & & $\mathbf{A}_{\mathrm{f} 1}$ & $-\sigma_{f 1}$ & $\mathbf{A}_{\mathrm{f} 2}$ & $-\sigma_{\mathrm{f} 2}$ & $\mathbf{A}_{\mathrm{f} 3}$ & $-\sigma_{f 3}$ & $\mathbf{A}_{\mathrm{f} 4}$ & $-\sigma_{f 4}$ & $\mathbf{A}_{\mathrm{f} 5}$ & $-\sigma_{\mathrm{f} 5}$ & \\
\hline $\mathrm{C} 2$ & Luo yang & 256.70963 & 1.99289 & 134.00571 & 2.0245 & 116.60713 & 2.11595 & 72.65835 & 1.99056 & 36.46797 & 2.01863 & 6779 \\
\hline C5 & Luo yang & 345.29542 & 2.02186 & 199.96298 & 2.04382 & 136.68084 & 2.14321 & 62.81304 & 1.99501 & 36.00166 & 2.0081 & 5248 \\
\hline $\mathrm{C} 8$ & Heijo Kyo & 314.50259 & 2.00869 & 140.51896 & 2.04034 & 105.44578 & 2.07985 & 41.23969 & 1.9886 & 24.08827 & 2.00917 & 1049 \\
\hline $\mathrm{C} 10$ & Heian Kyo & 285.15146 & 2.03047 & 143.38227 & 2.04861 & 81.77081 & 2.11992 & 55.64149 & 1.92818 & 23.62127 & 1.98605 & 1132 \\
\hline C11 & Balhae & 263.46053 & 2.02638 & 142.73511 & 2.04806 & 109.76223 & 2.15245 & 55.3479 & 1.99629 & 26.50927 & 1.99993 & 1447 \\
\hline $\mathrm{C} 16$ & Dadu & 345.85405 & 2.02923 & 199.75665 & 2.03836 & 124.38089 & 2.14522 & 72.32346 & 1.98619 & 30.78978 & 2.02437 & 3156 \\
\hline C19 & Beijing & 386.95322 & 2.01496 & 221.27391 & 2.02796 & 123.95823 & 2.14694 & 75.87624 & 1.9673 & 29.26393 & 2.0168 & 2428 \\
\hline $\mathrm{C} 20$ & Seoul & 310.36536 & 2.00486 & 135.44732 & 2.0044 & 105.10422 & 2.1405 & 45.1084 & 1.99355 & 22.16468 & 2.03669 & 896 \\
\hline $\mathrm{C} 21$ & Hué & 225.28692 & 1.98665 & 107.61288 & 2.03546 & 74.43002 & 2.17497 & 39.96131 & 1.97828 & 25.41877 & 2.03461 & 1551 \\
\hline \multicolumn{2}{|c|}{ Average } & 303.73102 & 2.01289 & 158.29953 & 2.03461 & 108.68223 & 2.13545 & 57.88554 & 1.98044 & 28.2584 & 2.01493 & $22,631.778$ \\
\hline
\end{tabular}

Table 6. The global average value of the allometric scaling in each wall-limited growth stage.

\begin{tabular}{cccccc}
\hline \multirow{2}{*}{ Wall Enclosure Hierarchy } & \multicolumn{2}{c}{ Local Fractal Parameter (in 9 cities) } & \multicolumn{2}{c}{ Least-Squares Average } & Scaling Capacity \\
\cline { 2 - 5 } & $\mathbf{D}_{\mathbf{l}}$ & $\mathbf{D}_{\mathbf{b}}$ & $\mathbf{D}_{\mathbf{f}}$ & $\mathbf{A}_{\mathbf{f}}\left(\mathbf{m}^{\mathbf{2}}\right)$ & $-\boldsymbol{\sigma}$ \\
\hline Outer wall & 0.99364 & 0.99683 & 2.00643 & 303.73102 & 2.01289 \\
Inner wall & 0.98303 & 0.99151 & 2.0173 & 158.29953 & 2.03461 \\
Palace wall & 0.93672 & 0.96836 & 2.06771 & 108.68223 & 2.13545 \\
Courtyard & 1.00997 & 1.00483 & 1.99023 & 2.88554 & 2.01493 \\
Hall envelope & 0.99261 & 0.99628 & 2.00746 & 131.37134 & 2.03566 \\
\hline Average & 0.983194 & 0.991562 & 2.017826 & \\
\hline
\end{tabular}




\subsection{Spatial Allometry and Structure Compactness}

For an empirical urban growth analysis, the city's phased allometry under the same scaling trajectory provides geometric self-similarity to help characterize its endogeneity, covering the range from the initial growth potential of that locale to the actual evolved urban boundary of the agglomeration carrier. The proportional form of the cross-section of the urban scaling trajectory due to the continuous wall enclosing also allows the walled cities to predict their future growth trend from a central-peripheral scaling law of the universal model. This implies a cascading distribution of the urban structure force with distance-dependent degeneration. In the mathematical model, the ordinary least-squares area $A_{f 1}$ of the outline of the city enclosed by any wall (in this study, we took the least-squares area $A_{f 5}$ from the wall enclosure range of the building as the initially presented city scale and to serve as the anchoring of urban agglomeration) in Equations (9) and (10) can be used for the initial location of urban allometry and shares self-similar growth (Table 5). The application of an allometric scaling (fractional abundance) can also be used to approach the proportionality of urban organizations in different endogeneity hierarchies. Furthermore, if we can ensure that the wall cross-sections' city scaling layer stays in constant proportion when it scales with the entire mass $\mathrm{M}$ (the proportional rate of endogeneity hierarchy) and assume the least-squares area $A_{f 5}$ as an actualized location for overall dynamics of the city growth, then a city's agglomeration entity based on the single logarithmic relationship can be described by the power-law-related distribution mechanism. The coherence of fractal abundance across whole city areas due to allometric scales can be used to predict the structural tensions or tightness of a walled urban system with its scaling changes from $A_{f 5}$.

By using Equation (11) to simulate the allometry of a city linearly scaled from a fixed location, the continuous set of walls surrounding the city outline could be obtained by the least-squares value $A_{f 5}$ (quasi-allometric scaling) in Table 5 . This estimated value is the initial emergence of city logarithmic size, which comes from the fundamental walled urban element's (building) feature. The proportional rate resulting from the hierarchical endogeneity of each city can be roughly expressed through this locational least-squares scaling $-\sigma$ and is displayed in Figure $6 a$. The results show high similarity in the allometric scaling of each city's growth state with the same locational growth radius (as the scaling trajectory) classification, revealing the whole system's mass and rates from the basic urban elements (buildings) to the highly aggregated land consumption borders (outer fortification). For the urban growth force with these radius constraints, the average scaling exponent from the least-squares scaling is around $\sigma 1 \approx 4.18, \sigma 2 \approx 5.51, \sigma 3 \approx 6.89, \sigma 4 \approx 7.80$, and $\sigma 5 \approx 9.15$. In the percentage calculation, their cross-sectional proportion is shown in Figure $6 \mathrm{~b}$. Since the land consumption rates in the locational growth radius are associated with the size of urban agglomeration, the compactness of these walled urban cross-sections is then proportional to the organic force accumulated by the locational scaling index, with its tensions degenerating, as shown in Figure 6c. Regardless of whether it is a phased allometric scaling or linearly related locational growth dynamics, the similarity of the scaling exponent at each homothetic walled urban profile is summarized as a common universal model. It is applicable for global access to every local Sino-influenced city and its hierarchical endogeneity. The results show that these cities have historically maintained relatively constant proportional regulations due to different historical conditions and growth force dynamics, suggesting a conceptualized organism model. For each proportional walled city scale's unfolding, the average value is in the respective local zoom index, namely, the dwelling scale with $12.5 \%$, the residential scale with $16.6 \%$, the community scale with $20.3 \%$, the small-town or capital scale with $23.3 \%$, and the city size with $27.3 \%$. 


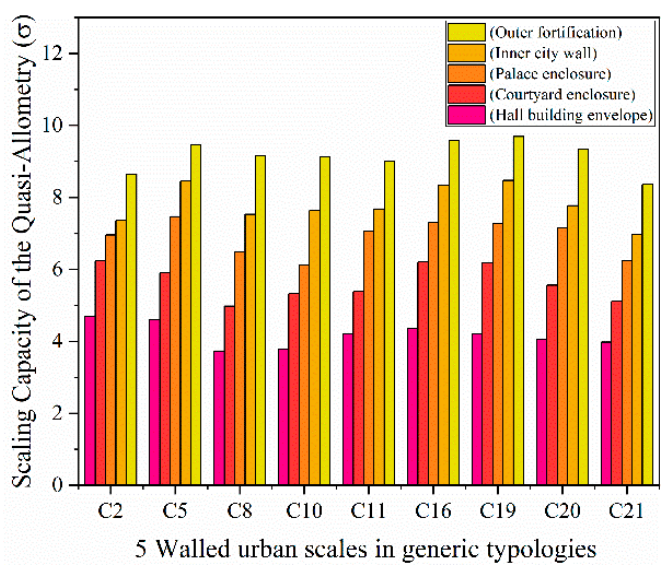

(a)

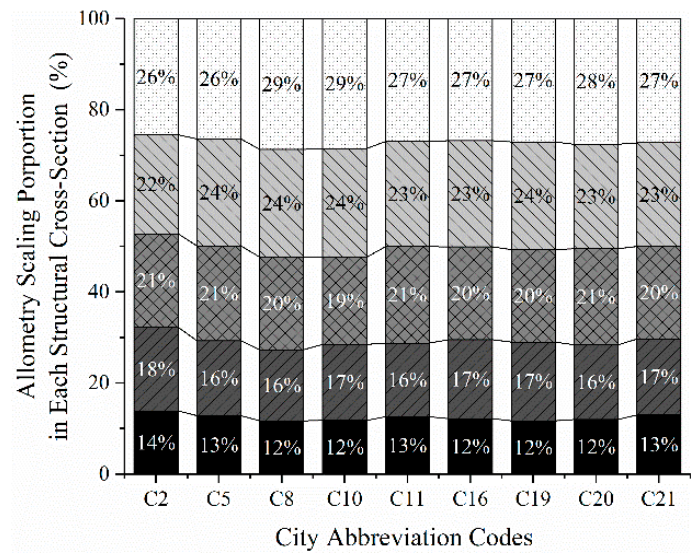

(b)

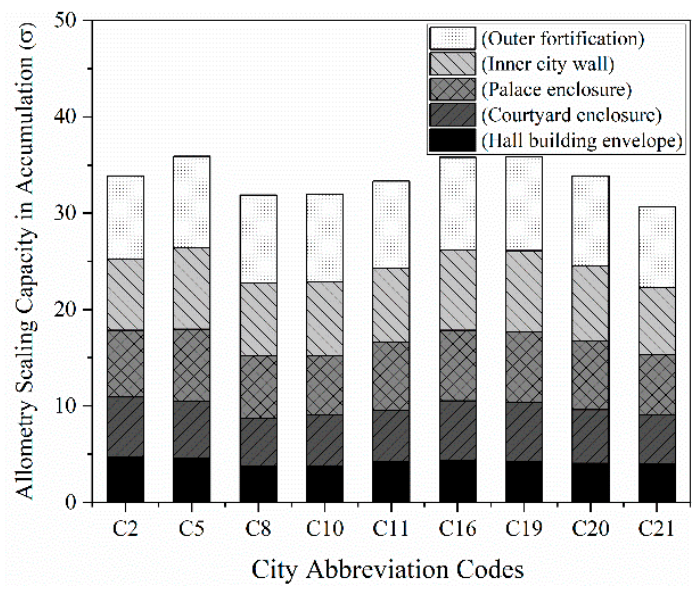

(c)

Figure 6. Scaling rate (proportionality) of the quasi-allometry property in different wall-embedded urban enclosures of its staged emergence: (a) Quasi-allometric property for each wall-enclosed urban range; (b) proportion of fitting of percentage; (c) accumulation of scaling capacity for initiator allometric.

Combining the regularity of urban allometry in Equations (11) and (12), a city of a distribution size with coherent walled urban profile constraints could be manifested as a dimensional boundary evolution process through power-law dependence scaling regularities, and the fluctuations observed around the generic trend are shown in Figure 7. The estimation results from nine cities all show a better fitting to the overall distribution trend line and reveal an approximate urban evolution from top to bottom. With the exception of C8 and C10 showing a relatively large fluctuation accident during the third evolution stage, all other cities have maintained a stable evolutionary state due to the quasi-least-squares allometry, which means that in addition to the endogenized land consumption rate, each of these cities' internal structure is less disturbed by other factors. The broken line represents the possible growth trajectory under a fixed scaling range, which reflects the local response of the quasi-least-square when it is embodied by the walled urban elements of the city distribution from the rate 1.011 to 1.648 . Owing to the implied fractal cascade relationship, the parameter values of this kind of allometry process can provide an optimized urban development model for the evolution of real cities. The fractal spectrum in this model can help describe a city's persistent dynamics $\lambda(r)$ in (12). This dynamic represents the average growth radius from the regional aggregation center to the edge of the aggregation pattern. The model was universally adapted to the city cluster integration algorithm. The clusters were aggregated upwards into spatial agglomeration and implemented downwards 
to the locational growth potential of specific artificial shapes. The result reflects a historical urban growth tension and its coherent growth, and it is closely related to the urban form and social and economic vitality.

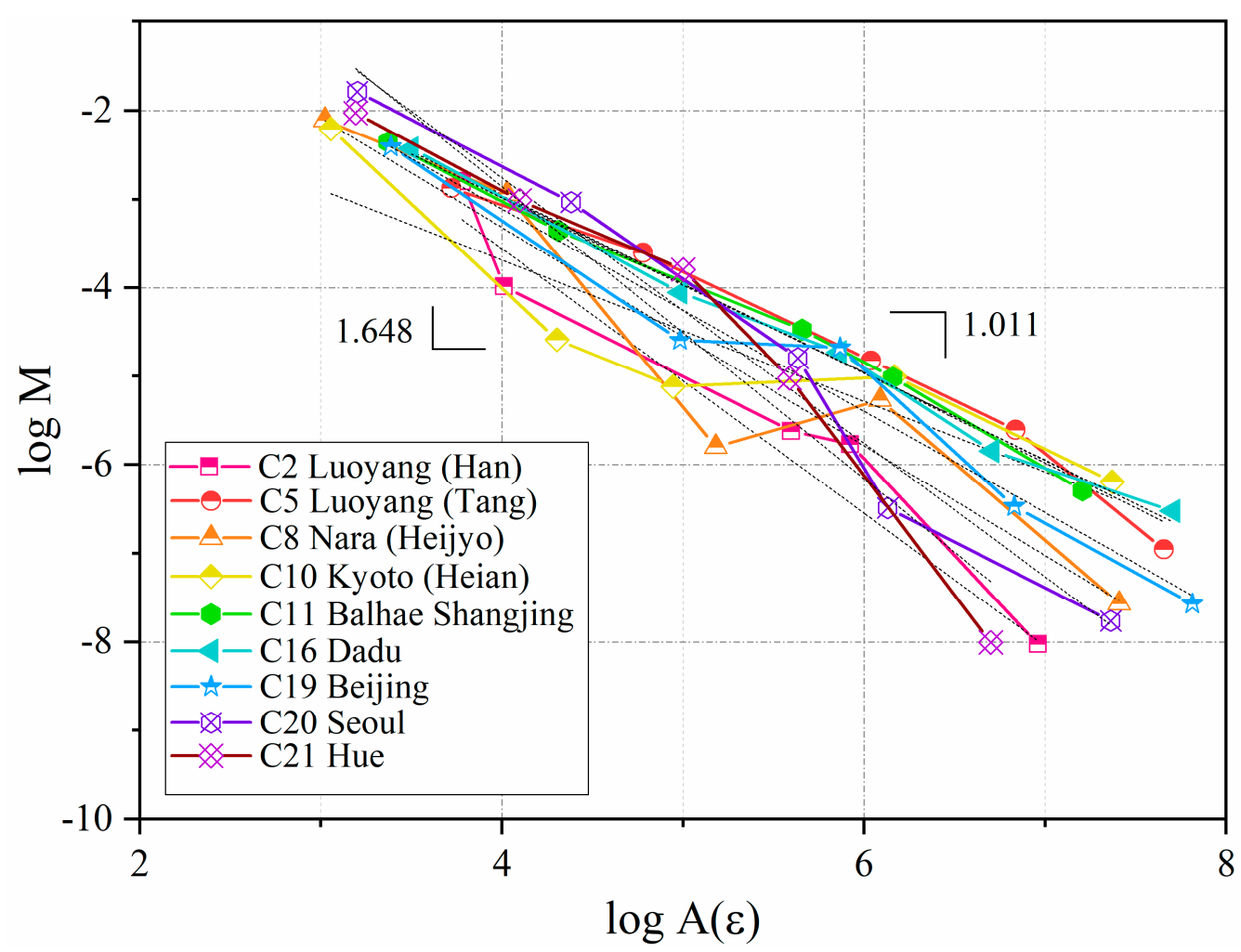

Figure 7. Double logarithmic relationship between radial profiles of least-squares fitting and agglomerate distribution embedding of the wall-enclosed boundary limit.

Consequently, after examining the overall historical pattern formation of Sino-influence walled cities, it can be found that their endogenous intra-urban process with multiple-wall enclosures shows similar scaling laws. As the initial positioning and manifestation of related dynamics to locale, the ordinary least-squares areas from localized urban-specific elements have established individual responses to the macro variables of the urban organism's adaptation. The overall tension generated (away from the growth center) can be evaluated by the continuity of walled boundary shifts (scaling ability) to assess the disturbance of the overall correlation dynamics. The wall-embedded city level can be considered a public facility that effectively organizes socioeconomic activity. It limits the development of the city in a self-sustaining manner within a reasonable range, and it ensures that the compactness is maintained in a relatively constant range and as a historical internal structural balance.

\section{Summary and Discussion}

Through the above practical analysis, regardless of whether the walled cities are based on the dispersion or aggregation of capital and information as a manifestation of the organic force of growth, the least-squares area based on the area-perimeter method estimate shows that these historical urban growth states exist with simple models. It is a response to the orderly induction of the relevant population size and the disorderly evolutionary process of social and economic activities. As a result of this research, the following questions have been clarified. First of all, owing to the influence of various driving forces in complexity dynamics, the agglomeration of cities in the current urban system is more likely to exhibit power-law-related allometric scaling, which is based on the double logarithmic relationship to the single logarithmic or even linear relationship [15,73-75]. In this study, because of 
the scaling trajectory throughout the walls' cross-section of the urban dimension layer (the unfolding framework of the social and political domain), the cities' internal structures showed a single logarithmic relationship within a universal function. The wall-organized city proportionally releases its organic force from the tightly maintained aggregation center and physically (using wall enclosures) points out the organization hierarchy in which the law of a city size increase enables wall-enclosed urban clusters in line with a standardized scaling trajectory. In this description of agglomerations located locally, cities can subdivide their population density and socioeconomic activity into any morphologically relevant range of features [76] as geometric properties are decentralized. It is related to the divergence of the local spatial living pattern under its individual rights.

Second, the regularity and coherence of allometric scaling make the boundaries of historical cities self-sustainable in spatial organization. In general, the greater the increase in the scaling index $-\sigma$, the weaker the city's ability to maintain its compactness through proportional expansion and contraction, and thus, the larger the radius interval required to achieve the same growth rate, and vice versa. In this study, the quasi-least-squares area of all cities showed an approximate scaling index for the cross-sectional fit of each land consumption hierarchy, which indicates the overall structural tension in a universal empirical model (Figure 6). Additionally, the allometry that is consistent between different urban cross-sections provides a law of proportionality, which can be judged by comparison with the squeezing or stretching of the regular allometric scaling in the zoom index. In theory, as the local responsive $\lambda(r)$, the scaling capacity varying in the fractal spectrum $\Delta \lambda=\left[\sigma_{(2+3+\ldots+n)} / n \sigma_{1}\right] \sigma_{1}$ from (12) reveals the growing tendency in Figure 8, where when the evolution is consistent within the diffusion process, $\Delta \lambda>1$; when the evolution stays static, $\Delta \lambda=1$; when the evolution is consistent within the aggregation process, $\Delta \lambda<1$. In practice, by adapting the scaling frequencies of different cross-sections, we can track the stability of an evolution process from its internal structure variations as the fluctuation of the fractal spectrum. For estimated cities, this frequency is determined by the isometric radius of locational walls that are inlaid (Figure 1), and the division of this frequency is considered to have a fixed proportion in the scaled regression (Table 6). The scaling exponent of iteration hierarchy is quantified by $\ln \mathrm{R}$ in Equation (12), which can be combined with the corresponding wall type characteristics to become a representative general type. The generative formula used in the space architecture $f(X n) \rightarrow f(X n-1)$ summarizes the relevant data and types in Table 7.

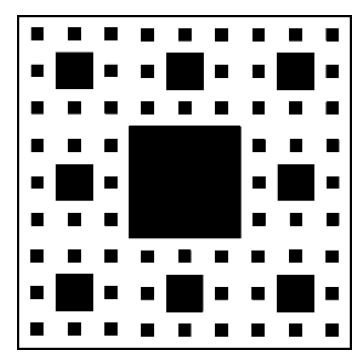

$\Delta \lambda>1$

(a) Consistent diffusion

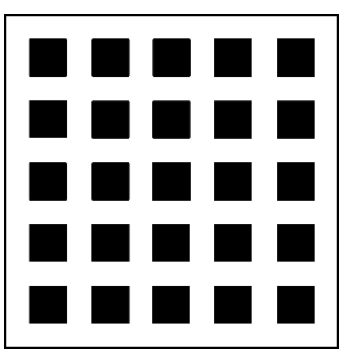

$\Delta \lambda=1$

(b) Static state Proportional evolution regulation

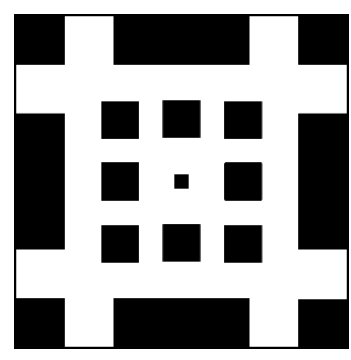

$\Delta \lambda<1$

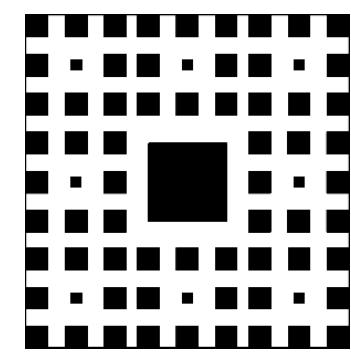

$\Delta \lambda>1$

$\begin{array}{ll}\text { (c) Consistent aggregation } & \text { (d) Disordered state }\end{array}$ Irregular evolution

Figure 8. Dimensional pattern changes in quasi-allometric scaling with fractal spectrum consistency. 
Table 7. Iteration schema for the wall-enclosed urban form extrusion and its correlated typologies and scaling.

\begin{tabular}{|c|c|c|c|c|c|c|}
\hline \multirow[b]{2}{*}{ Urban Spatial Rank } & \multicolumn{2}{|c|}{ Spatial Types of Correlation } & \multicolumn{4}{|c|}{ Representative Generic Typologies } \\
\hline & $\begin{array}{l}\text { Iteration } \\
\text { Step }\end{array}$ & Stratification Division & Urban Dimensions & $\begin{array}{c}\text { Introverted Urban } \\
\text { Significant }\end{array}$ & Growth Rate $\Delta \lambda$ & $\begin{array}{c}\operatorname{lnR} \text { (Local } \\
\text { Average) }\end{array}$ \\
\hline Rank 1 & $f(X n)$ & Outer fortification & City & Multiple Wall-surrounding & 6.293 & 80.27068 \\
\hline Rank 2 & $f(X n-1)$ & Inner city wall & Metropolitan area & Square-planning & 5.855 & 59.15584 \\
\hline Rank 3 & $f(X n-2)$ & Palace enclosure & District & Ward-well & 5.388 & 42.72298 \\
\hline Rank 4 & $f(X n-3)$ & Courtyard enclosure & Neighborhood & quadrangle-layout & 4.839 & 29.14126 \\
\hline Rank 5 & $f(X n-4)$ & Hall building envelope & Dwelling & Brackets arches & 4.18 & 18.41043 \\
\hline
\end{tabular}

Third, the scaling trajectory of the city size with continuous wall enclosures leads to these walled cities' involvement in evolutionary economic geography, which focuses on how to relationally link individual growth in contingent spaces [48]. Through the fractal zooming above, a microscope-style visual zooming behavior can intuitively reproduce the evolution of the internal structure of the "location-related urban tissue" at the material level (city), where the scaling adapted from the quasi-least-squares area to each wall-bounded land consumption region serves as a cascading distribution that is morphologically correlated with the environmental and socioeconomic outcome through fractal abundance. If the quasi-least-squares area is located in and represented by the artifactual urban element, and the element is ubiquitous in a texture that constitutes the urban material level, then the specificity of this cluster feature will replace the entire urban system to some extent, to serve as the statistics of clustering algorithms. In this study, the wall-enclosing space was considered to be suitable for this role in order to properly describe the spatial living pattern under different agglomeration scales and various wall enclosures.

In the existing data, five cities have retained their specific wall enclosure dimensions that reflect the city's fundamental element (building) size and also include the dimensions of this general feature in other urban dimensions. The fractal abundance is used here to classify the endogenized land consumption rate, whose start emerges at the initial location where the urban agglomeration is unfolded locally and is covered by local buildings. This hierarchical patrol system also reflects the traditional spatial life pattern in connection with political power, which can be regarded as the essence of the Sino-influenced urban structure [77]. For different scaling ranges of the historical built environment and socio-economic activities, the urban outlines of Sino-influenced walled cities are continuously and relationally depicted as a set of generally representative urban growth frameworks, corresponding to the structural elasticity of their agglomeration state, which is self-sustaining. Figure 9 portrays its general representative expansion and iterative steps of related dimensions.

This study did not explore historical cities with wall characteristics around the world, nor did we compare the current development status of the cities studied, which is considered to be the limitation of this study. The universal urban growth model derived from this study based on the laws of scaling and dimensional proportion of estimated walled cities cannot be fully adapted to all other historical cities with wall enclosures, since each city that builds its wall constructions is associated with different cultural and historical backgrounds. However, we can visit all these cities by applying the analytical methods in this study, because these cities in a historical walled environment can at least be regarded as spatial cells with complete boundaries that physically limit their normal growth. This means that the distribution probability of population density is artificially restricted by the historical texture of the city, whether in European cities (such as Paris, Nördlingen, Florence, or Milan) or other cities in Asia (such as Istanbul and Jerusalem): these cities were not included in this study. For the adaptation of the analytical model to different built environments, the characteristics of the wall enclosure can at least divide the historical city organization into three resolution levels and separate the objects from the complex urban texture through the correspondence of urban dimensions through microscopic zooming: specific public buildings (churches, city halls) are deployed as the initial agglomeration locales; inner city walls or city squares enclosed by buildings then provide the city's central places for the population to participate in social and economic activities and external fortifications at the threshold of the historical growth of the city. Therefore, the internal structure of walled cities in history 
can be summarized through the common land consumption process, from the quasi-least-squares area enclosed by specific buildings to the boundary of the urban spatial organization embedded in the external defensive walls. Although these cities are located in different places and have their own geographical shapes and sizes, their proportional organizational levels and socioeconomic evolution can still be unified as the maintenance of an organism under the expression of homothetic growth.

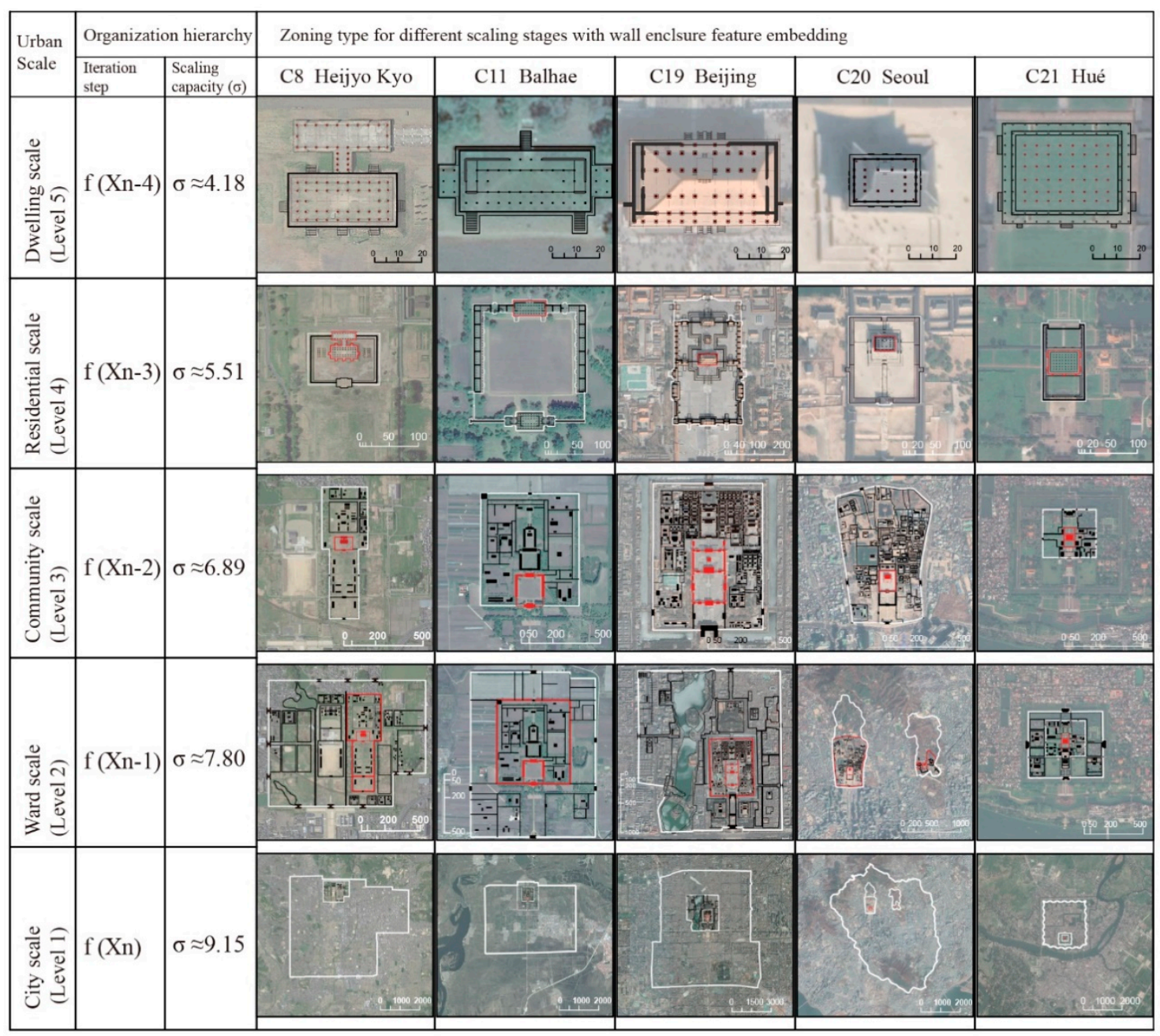

Figure 9. Zoning type-dependent form iterations with existing walled city rank evolution and organizational tension.

For the current urban development profile, the area-perimeter method that we used can hardly estimate its fuzzy development boundary. This does not mean that the current boundary dispersion is not measured. Recently, many advantageous techniques have been used to deal with such probabilistic scenarios. For example, the maximum likelihood method is used to divide the grid that appears in the city $[20,78]$. The goal definition method is used to extract the state of social and economic activities from natural cities [79] and through the matching of cellular automaton models to simulate the natural evolution of cities [80]. However, the disadvantage is that there are few methods that can clearly define the urban ontology boundaries of the original cities between the increasingly diffuse and integrated urban metropolitan areas, and introducing new methods would involve too many tasks, which was beyond the scope of this study. However, this is very important for the current allometry estimation of the city's radial effects and can help to assess its excessive growth rate (expressed by the spatiotemporal growth mechanism). 


\section{Conclusions}

The socioeconomic evolution pattern and relational spatial property of 21 Sino-influenced walled capital cities were evaluated through the area-perimeter allometric estimate. The urban form enclosed by multiple walls was used to embed the historical population agglomeration into the endogenous growth mechanism of a specific location. In this simplified mechanism, the central-peripheral radial effect corresponds to the internal urban structure as an organization actualization. The control of its tightness comes from the constraints of the urban physical factor scale on growth. We compared the allometric scaling laws of these cities with the same scaling trajectory, where the trajectory was proportionally divided into the same cross-sections with walled urban profiles (ranges) as the organizational hierarchies. We also approached these enclosing frequencies (compactness of these cities' internal structures) by adapting the coherence scaling from the quasi-least-squares allometry. The area of this smallest cross-section comes from the area-perimeter estimate of the possibility of location growth. The fractal abundance herein appropriately characterized the material environment extrusion through single logarithmic degeneration and linearly traced the socioeconomic evolution.

Through empirical research, we first found a high correlation between the endogenization of the wall-bounded land consumption level and the divergence of relevant spatial living patterns' emanation, in which the city sizes in the same cross-section of the wall-bounded urban dimension maintain an approximate zooming capability in accordance with their boundary allometry. Then, the geometric properties of the aggregated city volume generated a series of walled scaling patterns that were observed as ubiquitous urban cluster features and are proportional to the whole city size integrated by some clustering algorithms, although these cities showed different scales and shapes from real geographic spatial observations. In addition, we proposed to adopt an allometric scaling-based urban zoning type that classifies the contours of the walled city size according to their possibility scaling trajectory from the individual urban elements of that locale to the overall aggregation environment. Additionally, regression from different allometric scaling with respect to cluster hierarchy and cross-section proportion can be attributed to a generic scaling rate of urban dimensions in homothetic unfolding (zooming). In the allometric description, the fractal cascade model can restore the evolution process by tracking the radial effect of endogenized land consumption. In this study, this central-peripheral mechanism helped to describe the internal structure compactness of actual urban growth under the constraints of multiple walls. As agglomerated self-regulation, it provided a stable growth regularity to maintain the relevant city's internal maintenance at a historical equilibrium.

The highlight of this study was our proposal of a quasi-allometric scale that approximates and replaces the logarithmic city size so that the initial location of the urban agglomeration center can be anchored to the heterogeneity of the city's internal structure, and the wall enclosures as the physical constraints of human activities are attributed to the natural way (bottom-up approach) of defining cities, which the initial constraint provides through the building envelope and with the differentiation at any introverted spatial type, marking the populated sites without incorporating any census data. We further set forth the dual roles of these traditional wall enclosures' compound features that are both available for the spatial living pattern's classification and for the socioeconomic hierarchies' quantification. The self-similarity of consistent spatial allometry was introduced to characterize the organic force fluctuations of the wall enclosures' urban organization with a homothetic cross-section.

This is the first fractal investigation of the Sino-influenced wall-bounded urban morphology. For cities with a complex driving force of growth, the specific wall enclosures' scaling trajectory from the local-global and central-peripheral radius enables a continuous growth force restriction that causes cities to form a regular evolution rate and prevents the fast expansion of land consumption, making cities the physical tissues of the overall self-sustaining agglomeration. Additionally, although it is difficult to capture the real growth singularity from the current urban structure, through this study, we at least found a historical city growth model which physically locates the monocentric tradition into centripetal walls that form an organizational structure and proportionally limit the city size's expansion and socioeconomic activity. 
Author Contributions: Conceptualization, B.J.D. and J.H.; Data curation, H.Z.; Formal analysis, H.Z. and F.H.; Investigation, H.Z.; Methodology, H.Z. and J.H.; Project administration, B.J.D. and W.G.; Supervision, B.J.D., F.H., J.H. and W.G.; Visualization, H.Z.; Writing-original draft, H.Z.; Writing-review and editing, B.J.D. All authors have read and agreed to the published version of the manuscript.

Funding: This research received no external funding.

Conflicts of Interest: The authors declare no conflict of interest.

\section{Appendix A}

Table A1. Data survey and list of the earlier empirical and theoretical literature on 21 historical East Asia cities enclosures form and size.

\begin{tabular}{|c|c|c|c|}
\hline Abbr. & Name and Period & $\begin{array}{c}\text { Literature and Reliable Data Basis Reference of } \\
\text { Historical Surveys. }\end{array}$ & Scholar or Institute \\
\hline $\mathrm{C} 1$ & $\begin{array}{l}\text { Chang'an (Han) } \\
200 \text { B.C-25 }\end{array}$ & $\begin{array}{l}\text { *Review on Han Chang'an city site (in Chinese), Archaeology, } \\
\text { 2017-1, pp.9-16, http: } \\
\text { //www.kaogu.cn/uploads/soft/2017/20170906liuzhendong.pdf } \\
\text { *Study on Conservation of Chang An City Wall Ruins in Han } \\
\text { Dynasty, (in Chinese) } \\
\text { https://www.doc88.com/p-1438749324768.html } \\
\text { *Archaeological excavation and research on WeiYang palace, } \\
\text { Chang'an city, Han dynasty. (in Chinese), Relics and } \\
\text { Museolgy, 1995-3, pp.82-93 https: } \\
\text { //wenku.baidu.com/view/ddebe63a336c1eb91b375d15.html } \\
\text { *A jinzhong in the Weiyang Palace of Han Chang'an Castle: A } \\
\text { Study of the Domain (in Japanese), Gakushuin historical } \\
\text { review (45), 35-62, 2007-03, } \\
\text { URI:http://hdl.handle.net/10959/1004 }\end{array}$ & $\begin{array}{l}\text { 1. Liu Zhendong } \\
\text { 2. Hou Nan } \\
\text { 3. Liu Yufang } \\
\text { 4. Aoki Shunsuke }\end{array}$ \\
\hline $\mathrm{C} 2$ & $\begin{array}{l}\text { Luo yang (Han) } \\
\text { 25-190; 220-313 }\end{array}$ & $\begin{array}{l}\text { *Form and structures of capital cities in Wei, Jin, southern and } \\
\text { Northern Dynasties (in Chinese), Historical studies of ancient } \\
\text { and medieval China, 2015, Vol, No.35, pp 101-129. DOI: } \\
\text { 10.15840/amch.2015.35.004 } \\
\text { *New Discoveries and Research on the Structure in Han Wei } \\
\text { Luoyang cheng Imperial Palace Area (in Japanese and } \\
\text { Chinese), Hiraizumi studies 5, 1-11,13-22, 2017, NII Article ID } \\
\text { (NAID):120006343917 }\end{array}$ & $\begin{array}{l}\text { 1. Guo Xiang Qiang } \\
\text { 2. Matsumoto Keita \& } \\
\text { Guo Xiang Qiang }\end{array}$ \\
\hline $\mathrm{C} 3$ & $\begin{array}{l}\text { Ye City } \\
213-580\end{array}$ & $\begin{array}{l}\text { *The System of Capital City in medieval China from an } \\
\text { Archaeological Viewpoint (in Chinese and Korea), Middle } \\
\text { ages studies of Chinese, 2015, vol., no.35, pp. 131-164, DOI: } \\
\text { 10.15840/amch.2015.35.005 } \\
\text { *Form and structures of capital cities in Wei, Jin, southern and } \\
\text { Northern Dynasties (in Chinese), Historical studies of ancient } \\
\text { and medieval China,2015, Vol, No.35, pp 101-129. DOI: } \\
\text { 10.15840/amch.2015.35.004 }\end{array}$ & $\begin{array}{l}\text { 1. Han Jianhua } \\
\text { 2. Guo Xiang Qiang }\end{array}$ \\
\hline $\mathrm{C} 4$ & $\begin{array}{l}\text { Jian kang } \\
229-589\end{array}$ & $\begin{array}{l}\text { *Location of three cities in China: Jiankang, Chang'an, } \\
\text { Luoyang, Natural and society (in Japanese), Study on the } \\
\text { capital system (Nara Women's University Academic } \\
\text { Information Center), 2015, Vol, No.9, pp.53-68, URL: } \\
\text { http://hdl.handle.net/10935/4124 }\end{array}$ & 1. Seno, Tatsuhiko \\
\hline $\mathrm{C} 5$ & $\begin{array}{l}\text { Luo yang (Tang) } \\
\quad 605-938\end{array}$ & $\begin{array}{l}\text { *The multi capital system in the early Tang Dynasty (in } \\
\text { Japanese), Osaka Museum of history, Summary of research, } \\
\text { 2017.3, No.15, pp 1-18. http://www.mus-his.city.osaka.jp/ } \\
\text { education/publication/kenkyukiyo/pdf/no15/pdf15_01.pdf } \\
\text { *The plane, structure and form on Qianyang palace and } \\
\text { Qianyuan palace of Luoyang of Sui and Tang Dynasties (in } \\
\text { chinese), Journal of Chinese Architecture History, 2010, No.00, } \\
\text { pp 97-141 https: } \\
\text { //wenku.baidu.com/view/ef5f24470066f5335a8121f5.html }\end{array}$ & $\begin{array}{l}\text { 1. Ken'ichi Muramoto } \\
\text { 2. Wang Guixiang }\end{array}$ \\
\hline $\mathrm{C} 6$ & $\begin{array}{l}\text { Chang'an (Tang) } \\
\text { 582-940 }\end{array}$ & $\begin{array}{l}\text { *Planning techniques of CHANG'AN city in Sui and Tang } \\
\text { Dynasty (in Chinese), City Planning Review, 2009, Vol } 33 \text { (06), } \\
\text { pp 55-72, DOI: 10.3321/j.issn:1002-1329.2009.06.011 } \\
\text { *The System of Capital City in medieval China from an } \\
\text { Archaeological Viewpoint (in Chinese and Korea), Middle } \\
\text { ages studies of Chinese, 2015, vol., no.35, pp. 131-164, DOI: } \\
\text { 10.15840/amch.2015.35.005 } \\
\text { *Investigation report on the basic design of the environmental } \\
\text { restoration plan of Hanyuan Hall of Daming Palace, People } \\
\text { Republic of China (in Japanese), 2002.1 } \\
\text { http://open_jicareport.jica.go.jp/pdf/11774734.pdf }\end{array}$ & $\begin{array}{l}\text { 1. Wang Shusheng } \\
\text { 2. Han Jianhua } \\
\text { 3. Japan International } \\
\text { cooperation Agency }\end{array}$ \\
\hline
\end{tabular}


Table A1. Cont.

\begin{tabular}{|c|c|c|c|}
\hline Abbr. & Name and Period & $\begin{array}{c}\text { Literature and Reliable Data Basis Reference of } \\
\text { Historical Surveys. }\end{array}$ & Scholar or Institute \\
\hline $\mathrm{C} 7$ & $\begin{array}{l}\text { Fujiwara Kyo } \\
\quad 694-710\end{array}$ & $\begin{array}{l}\text { *Strip-block system in Fujihara Kyo-images and meaning (in } \\
\text { Japanese), Report of } 21 \text { century COE program Nara Women's } \\
\text { University Vol 16, pp.37-66, } \\
\text { URL:http://hdl.handle.net/10935/2736 } \\
\text { *ANNUAL BULLETIN of Nara National Cultural Properties } \\
\text { Research Institute 1997-II(in Japanese), } \\
\text { https://www.nabunken.go.jp/ }\end{array}$ & $\begin{array}{l}\text { 1. Hayashibe, 2. Hitoshi } \\
\text { Nara National Cultural } \\
\text { Properties Research } \\
\text { Institute }\end{array}$ \\
\hline $\mathrm{C} 8$ & $\begin{array}{l}\text { Heijo Kyo } \\
710-784\end{array}$ & $\begin{array}{l}\text { *ANNUAL BULLETIN of Nara National Cultural Properties } \\
\text { Research Institute } 1996 \text { (in Japanese), } \\
\text { https://www.nabunken.go.jp/ } \\
\text { *Historical significance of the construction of ancient Japanese } \\
\text { cities, in history of East Asia (in Japanese), Nichibunken } \\
\text { Japanese studies series, Vol. 42, pp. 95-138, DOI: } \\
\text { doi/10.15055/00005193 } \\
\text { *The restoration model of Heijo Palace (in Japanese), } \\
\text { ANNUAL BULLETIN of Nara National Cultural Properties } \\
\text { Research Institute 1966, pp 23-26, URL: } \\
\text { http://hdl.handle.net/11177/2629 }\end{array}$ & $\begin{array}{l}\text { 1. Nara National } \\
\text { Cultural Properties } \\
\text { Research Institute } \\
\text { 2. Inoue Kazuhito } \\
\text { 3. Honmi Keizou }\end{array}$ \\
\hline C9 & $\begin{array}{l}\text { Nagaoka Kyo } \\
784-794\end{array}$ & $\begin{array}{l}\text { *Nagaoka Kyo and temples (in Japanese), Study on the capital } \\
\text { system (Nara Women's University Academic Information } \\
\text { Center),2014.3, Vol.8, pp. 67-86, URL: } \\
\text { http://hdl.handle.net/10935/3643 } \\
\text { *Japan-China ancient city atlas (in Japanese), 2002.8, ISBN 13: } \\
\text { 9784878050121 }\end{array}$ & $\begin{array}{l}\text { 1. Koga Masahiro } \\
\text { 2. Nara National } \\
\text { Cultural Properties } \\
\text { Research Institute }\end{array}$ \\
\hline $\mathrm{C} 10$ & $\begin{array}{l}\text { Heian Kyo } \\
\quad 794-\end{array}$ & $\begin{array}{l}\text { *Japan-China ancient city atlas (in Japanese), 2002.8, ISBN 13: } \\
\text { 9784878050121 } \\
\text { *The designing of the roof for Fukko Shishin-den, restored } \\
\text { ceremonial hall: study of the imperial palace in the Kansei era } \\
\text { (4) (in Japanese), Journal of Architecture and Planning } \\
\text { (Transactions of AIJ) 2011, Vol.76(669), pp. 2183-2190, DOI: } \\
\text { 10.3130/aija.76.2183 }\end{array}$ & $\begin{array}{l}\text { 1. Nara National } \\
\text { Cultural Properties } \\
\text { Research Institute } \\
\text { 2. Kurimoto Yasuyo, } \\
\text { Uematsu Kiyoshi, Iwama } \\
\text { Kaori, Tani Naoki }\end{array}$ \\
\hline $\mathrm{C} 11$ & $\begin{array}{l}\text { Balhae Shangjing } \\
\quad 755-929\end{array}$ & $\begin{array}{l}\text { *A Restoration Study of the No.2 and the No.5 Building of the } \\
\text { Balhae Shanging Palace (in Chinese), Dissertation for the } \\
\text { Master Degree, Harbin Institute of Technology, 2008.6, DOI: } \\
\text { 10.7666/d.D255105 } \\
\text { *Restoration Analysis on the Main Building Groups of } \\
\text { Shangjing City in Balhae State (in Chinses), Dissertation for } \\
\text { the Doctoral Degree, Harbin Institute of Technology, 2014.7, } \\
\text { DOI: 10.7666/d.D751424 } \\
\text { *Historical significance of the construction of ancient Japanese } \\
\text { cities, in history of East Asia (in Japanese), Nichibunken } \\
\text { Japanese studies series, Vol. 42, pp. 95-138, DOI: } \\
\text { doi/10.15055/00005193 }\end{array}$ & $\begin{array}{l}\text { 1. Liu Chuan } \\
\text { 2. Sun Zhimin } \\
\text { 3. Inoue Kazuhito }\end{array}$ \\
\hline $\mathrm{C} 12$ & $\begin{array}{l}\text { Bianjing } \\
907-1127\end{array}$ & $\begin{array}{l}\text { *Discussion on the Yingzao Chi of the Northern Song Dynasty } \\
\text { Referring to the Archaeological Discovery of the Outer City of } \\
\text { the Dongjing of the Northern Song Dynasty (in Chinese), } \\
\text { Cultural Relics, 2018, Vol (2), } \\
\text { http://www.kaogu.cn/uploads/soft/2018/20180327beisong.pdf } \\
\text { *On the Old City of the Northern Song Capital of Kaifeng (in } \\
\text { Japanese), Studies in Urban Culture, 2014, Vol. 16, pp. 79-91, } \\
\text { DOI: info:doi/10.24544/ocu.20171213-053 }\end{array}$ & $\begin{array}{l}\text { 1. Liu Chunying } \\
\text { 2. Kazuo Kubota }\end{array}$ \\
\hline $\mathrm{C} 13$ & $\begin{array}{l}\text { Lin'an } \\
1129-1287\end{array}$ & $\begin{array}{l}\text { *Dream back to the Southern Song Dynasty, restoration the } \\
\text { "underground imperial city" from historical obliterates (in } \\
\text { Chinese), Hangzhou, 2017, Vol. 22, pp. 14-17, DOI: } \\
\text { 10.16639/j.cnki.cn33-1361/d.2017.22.003 } \\
\text { *The Study on the Spatial and Timing Structure of Festival } \\
\text { Activities in Lin'an City during the Southern Song Period (in } \\
\text { Chinese), Journal of Chinese Historical Geography, 2008.10, } \\
\text { Vol. 23, No.4, pp. 5-22, } \\
\text { http://www.doc88.com/p-7798909440293.html }\end{array}$ & $\begin{array}{l}\text { 1. Ren Riyin, Yao Minlv } \\
\text { 2. Zhang Xiaohong, Mou } \\
\text { Zhenyu, Chen Li, Ding } \\
\text { Yannan }\end{array}$ \\
\hline $\mathrm{C} 14$ & $\begin{array}{l}\text { Jin Zhongdu } \\
1153-1251\end{array}$ & $\begin{array}{l}\text { *Research on the Urban Morphology and Foundations of } \\
\text { Building Complexes in Yuan Dynasty Capital City (in } \\
\text { Chinese), Dissertation for the Doctoral Degree, Tsing Hua } \\
\text { University, 2007, http://kns.cnki.net/KCMS/detail/detail.aspx? } \\
\text { dbcode=CDFD\&filename=2008088115.nh } \\
\text { *The History Study of Liao-Jin Yanjing City: Reviewing Urban } \\
\text { Archaeology Methodology (in Chinese), Palace Museum } \\
\text { Journal, 2016, Vol.02, pp. 77-97, DOI: } \\
\text { 10.16319/j.cnki.0452-7402.2016.02.007 }\end{array}$ & $\begin{array}{l}\text { 1. Jiang Dongcheng } \\
\text { Liu Wei }\end{array}$ \\
\hline
\end{tabular}


Table A1. Cont.

\begin{tabular}{|c|c|c|c|}
\hline Abbr. & Name and Period & $\begin{array}{c}\text { Literature and Reliable Data Basis Reference of } \\
\text { Historical Surveys. }\end{array}$ & Scholar or Institute \\
\hline C15 & $\begin{array}{l}\text { Yuan Xanadu } \\
1260-1267\end{array}$ & $\begin{array}{l}{ }^{*} \text { City Planning of Newly-built Cities of Mongol Empire (in } \\
\text { Chinese), Research of China's Frontier Archaeology, 2015, Vol. } \\
\text { 17, pp. 313-342, http://kg.lsxy.ruc.edu.cn/uploadfile/2016/1218/ } \\
\text { 20161218104217107.pdf }\end{array}$ & 1. Liu Wei \\
\hline $\mathrm{C} 16$ & $\begin{array}{c}\text { Dadu } \\
1267-1421\end{array}$ & $\begin{array}{l}\text { *Research on the Urban Morphology and Foundations of } \\
\text { Building Complexes in Yuan Dynasty Capital City (in } \\
\text { Chinese), Dissertation for the Doctoral Degree, Tsing Hua } \\
\text { University, 2007, http://kns.cnki.net/KCMS/detail/detail.aspx? } \\
\text { dbcode=CDFD\&filename=2008088115.nh } \\
\text { *Study on the restoration of the palace in Dadu of the Yuan } \\
\text { Dynasty (in Chinese), Acta Archaeologica Sinica, 1993, Vol.01, } \\
\text { pp. 109-151, https://www.ixueshu.com/document/ } \\
\text { 59300c641802d90d318947a18e7f9386.html } \\
\text { *City Planning of Newly-built Cities of Mongol Empire (in } \\
\text { Chinese), Research of China's Frontier Archaeology, 2015, Vol. } \\
\text { 17, pp. 313-342, http://kg.lsxy.ruc.edu.cn/uploadfile/2016/1218/ } \\
\text { 20161218104217107.pdf }\end{array}$ & $\begin{array}{l}\text { 1. Jiang 2. Dongcheng } \\
\text { 3. Fu Xinian } \\
\text { Liu Wei }\end{array}$ \\
\hline $\mathrm{C} 17$ & $\begin{array}{l}\text { Ming Zhongdu } \\
\text { 1369-1375 }\end{array}$ & $\begin{array}{l}\text { *Form and Planning of Newly-Built Capital Cities in Late } \\
\text { Imperial China: Archaeological restoration and comparative } \\
\text { study of the central capitals of the Yuan and Ming dynasties } \\
\text { (in Chinese), City Planning Review, 2018, Vol. 42(8), pp. 57-65, } \\
\text { DOI: } 10.11819 / \text { cpr20180810a }\end{array}$ & 1. Chen Xiao, Sun Hua \\
\hline $\mathrm{C} 18$ & $\begin{array}{l}\text { Nanjing } \\
1375-1421\end{array}$ & $\begin{array}{l}\text { *Form and Planning of Newly-Built Capital Cities in Late } \\
\text { Imperial China: Archaeological restoration and comparative } \\
\text { study of the central capitals of the Yuan and Ming dynasties } \\
\text { (in Chinese), City Planning Review, 2018, Vol. 42(8), pp. 57-65, } \\
\text { DOI: 10.11819/cpr20180810a } \\
\text { *Study on planning strategies of the Forbidden City of Ming } \\
\text { Dynasty in Nanjing (in Chinese), Journal of Shandong } \\
\text { University of Architecture and Engineering, 2006, Vol. 21(2), } \\
\text { pp. 122-128, DOI: } 10.3969 / \text { j.issn.1673-7644.2006.02.006 }\end{array}$ & $\begin{array}{l}\text { 1. Chen Xiao, Sun Hua } \\
\text { 2. Deng Shenghui, Yao } \\
\text { Yifeng }\end{array}$ \\
\hline C19 & $\begin{array}{l}\text { Beijing } \\
1421-\end{array}$ & $\begin{array}{l}\text { *Form and Planning of Newly-Built Capital Cities in Late } \\
\text { Imperial China: Archaeological restoration and comparative } \\
\text { study of the central capitals of the Yuan and Ming dynasties } \\
\text { (in Chinese), City Planning Review, 2018, Vol. 42(8), pp. 57-65, } \\
\text { DOI: 10.11819/cpr20180810a } \\
\text { *Peking und Umgebung (Map: col. ; } 76 \times 68 \mathrm{~cm} \text { ), Berlin: } \\
\text { Reichsamt für Landesaufnahme, 1907, Digital ID: } \\
\text { http://hdl.loc.gov/loc.gmd/g7824b.ct001944 } \\
\text { *National Beiping Palace Museum plan (Map; } 104.5 \times 148 \mathrm{~cm} \text { ), } \\
\text { 1948 }\end{array}$ & $\begin{array}{l}\text { 1. Chen Xiao, Sun Hua } \\
\text { 2. Library of Congress } \\
\text { Geography and Map } \\
\text { Division Washington, } \\
\text { D.C. 20540-4650 USA dcu } \\
\text { 3.Beiping Palace } \\
\text { Museum }\end{array}$ \\
\hline $\mathrm{C} 20$ & $\begin{array}{l}\text { Seoul } \\
1394-\end{array}$ & $\begin{array}{l}\text { *A Study on the Designation in Korean Traditional Space } \\
\text { design Text (in Korea), Korean Institute of Interior Design } \\
\text { Journal, 2007, Vol. 16, No.4, pp. 31-38, UCI: } \\
\text { G704-000249.2007.16.4.013 } \\
\text { *Report on the basic restoration and repair plan of Jingfu } \\
\text { Palace, 1994, http://116.67.83.213/NEW_PDF/EM017464.pdf }\end{array}$ & $\begin{array}{l}\text { 1. Park Kyung-Ae } \\
\text { 2. Korean Cultural } \\
\text { Heritage Administration }\end{array}$ \\
\hline $\mathrm{C} 21$ & $\begin{array}{l}\text { Hué } \\
1804-1945\end{array}$ & $\begin{array}{l}\text { *Reconstruction study for decorative painting at the 'Can } \\
\text { Chanh Dien', main palace of the Nguyen dynasty (in } \\
\text { Japanese), Dissertation for the Doctoral Degree, Waseda } \\
\text { University, 2013, URL: http://id.ndl.go.jp/bib/024807810 } \\
\text { *9005 Relation between Plans of Places and Bloc Plan: Studies } \\
\text { on the Imperial Palace of Hue, Vietnam, in the Nguyen } \\
\text { Dynasty (Part 154) (in Japanese), Proceeding of the } \\
\text { architectural research meetings, Kanto Chapter, Architectural } \\
\text { Institute of Japan, 2011, Vol. 81, pp. 475-478. } \\
\text { https://www.aij.or.jp/paper/detail.html?productId=394004 } \\
\text { *Analysis on the Measurement in Planning of Disposition (II): } \\
\text { Studies on the Imperial Palace of Hue, Viet Nam, in the } \\
\text { Nguyen Dynasty (Part 3) (in Japanese), Summaries of technical } \\
\text { papers of Annual Meeting Architectural Institute of Japan. F-2, } \\
\text { History and theory of architecture, 1995, pp. 531-532. } \\
\text { https://www.aij.or.jp/paper/detail.html?productId=271246 }\end{array}$ & $\begin{array}{l}\text { 1. Saito shiomi } \\
\text { Kanayama Emiko, } \\
\text { Nakagawa Takeshi, } \\
\text { Kitani Kenta } \\
\text { 2,3. Tsuchiya Takeshi, } \\
\text { Nakagawa Takeshi, } \\
\text { Nishimoto Shin-ichi, } \\
\text { Takano Keiko, } \\
\text { Nakazawa Shin-ichiro, }\end{array}$ \\
\hline
\end{tabular}




\section{References}

1. Altieri, M.A. The Ecological Role of Biodiversity in Agroecosystems. Agric. Ecosyst. Environ. 1999, 74, $19-31$. [CrossRef]

2. Newbold, T.; Hudson, L.N.; Arnell, A.P.; Contu, S.; De Palma, A.; Ferrier, S.; Hill, S.L.L.; Hoskins, A.J.; Lysenko, I.; Phillips, H.R.P.; et al. Has Land Use Pushed Terrestrial Biodiversity beyond the Planetary Boundary? A Global Assessment. Science 2016, 353, 288-291. [CrossRef]

3. Friedmann, J. The World City Hypothesis. Dev. Chang. 1986, 17, 69-83. [CrossRef]

4. Urry, J. The Complexities of the Global. Theory Cult. Soc. 2005, 22, 235-254. [CrossRef]

5. Alonso, W. Location and Land Use; Harvard University Press: Cambridge, MA, USA, 1964.

6. Alperovich, G. Scale Economies and Diseconomies in the Determination of City Size Distribution. J. Urban Econ. 1982, 12, 202-213. [CrossRef]

7. Capozza, D.R.; Helsley, R.W. The Stochastic City. J. Urban Econ. 1990, 28, 187-203. [CrossRef]

8. Mills, D.E. Growth, Speculation and Sprawl in a Monocentric City. J. Urban Econ. 1981, 10, $201-226$. [CrossRef]

9. Benguigui, L.; Czamanski, D.; Marinov, M. The Dynamics of Urban Morphology: The Case of Petah Tikvah. Environ. Plan. B Plan. Des. 2001, 28,447-460. [CrossRef]

10. Capozza, D.R.; Helsley, R.W. The Fundamentals of Land Prices and Urban Growth. J. Urban Econ. 1989, 26, 295-306. [CrossRef]

11. Chakrabarti, B.K.; Benguigui, L.G. Statistical Physics of Fracture and Breakdown in Disordered Systems; Clarendon Press: Broadbridge Alderley, UK, 1997.

12. Fujita, M.; Ogawa, H. Multiple Equilibria and Structural Transition of Non-Monocentric Urban Configurations. Reg. Sci. Urban Econ. 1982, 12, 161-169. [CrossRef]

13. Krugman, P.R. The Self Organizing Economy; Blackwell Publishers: Cambridge, MA, USA; Oxford, UK, 1996.

14. Allen, P.M. Cities and Regions as Self-Organizing Systems: Models of Complexity. In Proceedings of the Brazilian and Ibero-American Congress on Social Housing; Routledge: London, UK, 1997.

15. Gabaix, X. Zipf's Law for Cities: An Explanation. Q. J. Econ. 1999, 114, 739-767. [CrossRef]

16. Glazer, A.; Mark, G.; Priya, R. Consumption Variety and Urban Agglomeration. Reg. Sci. Urban Econ. 2003, 33, 653-661. [CrossRef]

17. Scott, A.J. Global City-Regions: Trends, Theory, Policy; Oxford University Press: Oxford, UK, 2001.

18. Bettencourt, L.M.A. The Origins of Scaling in Cities. Science 2013, 340, 1438-1441. [CrossRef] [PubMed]

19. Makse, H.A.; Havlin, S.; Stanley, H.E. Modelling Urban Growth Patterns. Nature 1995, 377, $608-612$. [CrossRef]

20. Rozenfeld, H.D.; Rybski, D.; Gabaix, X.; Makse, H.A. Dimension of Strange Attractors. Phys. Rev. Lett. 1980, $45,1175-1178$.

21. Portnov, B.A.; Schwartz, M. Urban Clusters As Growth Foci. J. Reg. Sci. 2009, 49, 287-310. [CrossRef]

22. Nordbeck, S. Urban Allometric Growth. Geogr. Ann. Ser. B Hum. Geogr. 1971, 53, 54-67. [CrossRef]

23. Martin, D. Automatic Neighbourhood Identification from Population Surfaces. Comput. Environ. Urban Syst. 1998, 22, 107-120. [CrossRef]

24. Batty, M.; Longley, P.A. Fractal Cities: A Geometry of Form and Function; Academic Press: London, UK, 1994.

25. Foster, J. From Simplistic to Complex Systems in Economics. Camb. J. Econ. 2005, 29, 873-892. [CrossRef]

26. Holland, J.H. Signals and Boundaries: Building Blocks for Complex Adaptive Systems; MIT Press: Cambridge, MA, USA, 2012.

27. Jones, M. Phase Space: Geography, Relational Thinking, and Beyond. Prog. Hum. Geogr. 2009, 33, 487-506. [CrossRef]

28. Rozenfeld, H.D.; Rybski, D.; Gabaix, X.; Makse, H.A. The Area and Population of Cities: New Insights from a Different Perspective on Cities. Am. Econ. Rev. 2011, 101, 2205-2225. [CrossRef]

29. Yeung, H.W.C. Rethinking Relational Economic Geography. Trans. Inst. Br. Geogr. 2005, 30, 37-51. [CrossRef]

30. Skinner, G.W. The City in Late Imperial China; Stanford University Press: Stanford, CA, USA, 1977; Volumes 275-315, pp. 211-249.

31. Chen, F.; Ombretta, R. Preserving the Cultural Identity of Chinese Cities in Urban Design through a Typomorphological Approach. Urban Des. Int. 2009, 14, 36-54. [CrossRef] 
32. Xu, M.; Yang, Z. Design History of China's Gated Cities and Neighbourhoods: Prototype and Evolution. Urban Des. Int. 2009, 14, 99-117. [CrossRef]

33. Smith, M.E. Form and Meaning in the Earliest Cities: A New Approach to Ancient Urban Planning. J. Plan. Hist. 2007, 6, 3-47. [CrossRef]

34. Jin, W. The Historical Development of Chinese Urban Morphology. Plan. Perspect. 1993, 8, 20-52. [CrossRef]

35. Zhang, G.; Wang, L. Urban Planning and Development in China and Other East Asian Countries; Springer: Singapore, 2019.

36. Whitehand, J.W.R.; Gu, K. Research on Chinese Urban Form: Retrospect and Prospect. Prog. Hum. Geogr. 2006, 30, 337-355. [CrossRef]

37. Zhu, J. Criticality in between China and the West. J. Archit. 2005, 10, 479-498. [CrossRef]

38. Elvin, M. The Pattern of the Chinese Past; Stanford University Press: Stanford, CA, USA, 1973.

39. Ioannides, Y.M.; Zhang, J. Walled Cities in Late Imperial China. J. Urban Econ. 2017, 97, 71-88. [CrossRef]

40. Whitehand, J.W.; Morton, N.J. Morton. Urban Morphology and Planning: The Case of Fringe Belts. Cities 2004, 21, 275-289. [CrossRef]

41. Jacobs, J. The Economy of Cities; Vintage Press: Visalia, CA, USA, 1969.

42. Clawson, M. Urban Sprawl and Speculation in Suburban Land. Land Econ. 1962, 38, 99-111. [CrossRef]

43. Funo, S. Ancient Chinese Capital Models-Measurement System in Urban Planning. Proc. Jpn. Acad. Ser. B Phys. Biol. Sci. 2017, 93, 724-745. [CrossRef]

44. Chinese Academy of Social Sciences (CASS). Available online: http://kaogu.cssn.cn (accessed on 22 February 2019).

45. Nara National Research Institution for Culture Properties. Available online: http://www.nabunken.go.jp (accessed on 6 December 2018).

46. Culture Heritage Administration of Korea (CHA). Available online: http://English.cha.go.kr (accessed on 7 January 2019).

47. LocaSpace Viewer center. Available online: http://www.locaspace.cn/LSV.jsp (accessed on 22 May 2019).

48. Beinhocker, E.D. The Origin of Wealth: Evolution, Complexity, and the Radical Remaking of Economics; Random House Business Books: London, UK, 2007.

49. Wohl, S. Considering How Morphological Traits of Urban Fabric Create Affordances for Complex Adaptation and Emergence. Prog. Hum. Geogr. 2016, 40, 30-47. [CrossRef]

50. Benguigui, L.; Czamanski, D. Simulation Analysis of the Fractality of Cities. Geogr. Anal. 2004, 36, 69-84. [CrossRef]

51. Batty, M.; Longley, P.; Fotheringham, S. Urban Growth and Form: Scaling, Fractal Geometry, and Diffusion-Limited Aggregation. Environ. Plan. A 1989, 21, 1447-1472. [CrossRef]

52. Batty, M.; Kim, K.S. Form Follows Function: Reformulating Urban Population Density Functions. Urban Stud. 1992, 29, 1043-1069. [CrossRef]

53. Frankhauser, P. Fractal Geometry of Urban Patterns and Their Morphogenesis. Discret. Dyn. Nat. Soc. 1998, 2, 127-145. [CrossRef]

54. White, R.; Engelen, G. Cellular Automata and Fractal Urban Form: A Cellular Modelling Approach to the Evolution of Urban Land-Use Patterns. Environ. Plan. A 1993, 25, 1175-1199. [CrossRef]

55. Benguigui, L.; Blumenfeld-Lieberthal, E.; Czamanski, D. The Dynamics of the Tel Aviv Morphology. Environ. Plan. B Plan. Des. 2006, 33, 269-284. [CrossRef]

56. Chen, Y. Characterizing Growth and Form of Fractal Cities with Allometric Scaling Exponents. Discret. Dyn. Nat. Soc. 2010, 2010, 1-22. [CrossRef]

57. Longley, P.A.; Batty, M. On the Fractal Measurement of Geographical Boundaries. Geogr. Anal. 2010, 21, 47-67. [CrossRef]

58. Foroutan-pour, K.; Dutilleul, P.; Smith, D.L. Advances in the Implementation of the Box-Counting Method of Fractal Dimension Estimation. Appl. Math. Comput. 1999, 105, 195-210. [CrossRef]

59. Lovejoy, S.D.A.A.; Schertzer, D.; Tsonis, A.A. Functional Box-Counting and Multiple Elliptical Dimensions in Rain. Science 1987, 235, 1036-1038. [CrossRef] [PubMed]

60. Mandelbrot, B.B. The Fractal Geometry of Nature; W.H. Freeman and Company: New York, NY, USA, 1982.

61. Chen, Y. Spatial Autocorrelation Approaches to Testing Residuals from Least Squares Regression. PLoS ONE 2016, 11, e0146865. [CrossRef] [PubMed] 
62. Chen, Y. Fractal Analytical Approach of Urban Form Based on Spatial Correlation Function. Chaos Solitons Fractals 2013, 49, 47-60. [CrossRef]

63. Batty, M.; Carvalho, R.; Hudson-Smith, A.; Milton, R.; Smith, D.; Steadman, P. Scaling and Allometry in the Building Geometries of Greater London. Eur. Phys. J. B 2008, 63, 303-314. [CrossRef]

64. Bettencourt, L.M.; Lobo, J.; Helbing, D.; Kühnert, C.; West, G.B. Growth, Innovation, Scaling, and the Pace of Life in Cities. Proc. Natl. Acad. Sci. USA 2007, 104, 7301-7306. [CrossRef]

65. Lobo, J.; Bettencourt, L.M.; Strumsky, D.; West, G.B. Urban Scaling and the Production Function for Cities. PLOS ONE 2013, 8, e58407. [CrossRef]

66. Chen, Y.; Feng, J. Fractal-Based Exponential Distribution of Urban Density and Self-Affine Fractal Forms of Cities. Chaos Solitons Fractals 2012, 45, 1404-1416. [CrossRef]

67. Lee, Y. An Allometric Analysis of the US Urban System: 1960-80. Environ. Plan. A 1989, 21, 463-476. [CrossRef]

68. Feder, M.; Weinstein, E. Parameter Estimation of Superimposed Signals Using the EM Algorithm. IEEE Trans. Acoust. Speech Signal Process. 1988, 36, 477-489. [CrossRef]

69. Chen, Y.; Wang, J.; Feng, J. Spatial Entropy and Fractal Dimension of Urban form. Entropy 2017, 19, 600. [CrossRef]

70. Bak, P.; Shobo, B. How Nature Works: The Science of Self-Organized Criticality; Copernicus Publishing: Bethel Park, PA, USA, 1996.

71. Chen, Y.; Jiang, S. An Analytical Process of the Spatio-Temporal Evolution of Urban Systems Based on Allometric and Fractal Ideas. Chaos Solitons Fractals 2009, 39, 49-64. [CrossRef]

72. Chen, Y. A Set of Formulae on Fractal Dimension Relations and Its Application to Urban Form. Chaos Solitons Fractals 2013, 54, 150-158. [CrossRef]

73. Eeckhout, J. Gibrat's Law for (All) Cities. Am. Econ. Rev. 2004, 94, 1429-1451. [CrossRef]

74. Mori, T.; Smith, T.E. An Industrial Agglomeration Approach to Central Place and City Size Regularities. J. Reg. Sci. 2011, 51, 694-731. [CrossRef]

75. Sornette, D. Self-Organized Slimming of Power Law Tails by Increasing Market Returns. Phys. A Stat. Mech. Its Appl. 2002, 309, 403-418. [CrossRef]

76. Sornette, D. Probability Distributions in Complex Systems. Encycl. Complex. Syst. Sci. 2009, 7, 7009-7024.

77. Ming-Wei, L.; Kwang, P.L. An Outline History of the Chinese Capital Morphology: The Agglomeration, Differentiation and the Procedures of Institutionalization of the Chinese Capitals before Medieval City Revolution. J. Build. Plan. Natl. Taiwan Univ. 2009, 16, 79-119.

78. Holmes, T.J.; Lee, S. Cities as Six-by-Six-Mile Squares: Zipf's Law? NBER Chapters; University of Chicago Press: Chicago, IL, USA, 2010; pp. 105-131.

79. Borruso, G. Network Density and the Delimitation of Urban Areas. Trans. GIS 2003, 7, 177-191. [CrossRef]

80. Alaei Moghadam, S.; Karimi, M.; Habibi, K. Simulating Urban Growth in a Megalopolitan Area Using a Patch-based Cellular Automata. Trans. GIS 2018, 22, 249-268. [CrossRef]

(C) 2020 by the authors. Licensee MDPI, Basel, Switzerland. This article is an open access article distributed under the terms and conditions of the Creative Commons Attribution (CC BY) license (http://creativecommons.org/licenses/by/4.0/). 